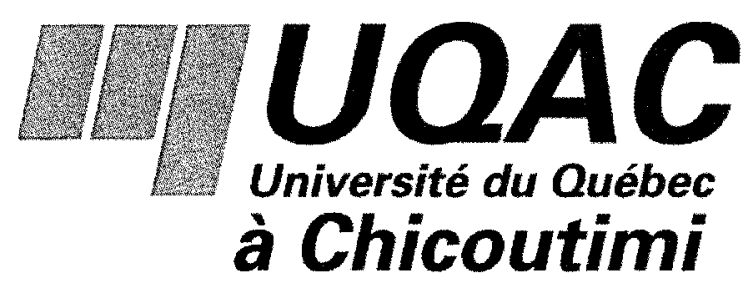

Big Five personality factors and individual performance

\begin{abstract}
A Thesis Submitted to
The Department of Economic and Administrative sciences in Partial Fulfillment of the Requirements for the Degree of Master of Organisations Management
\end{abstract}

By: Nesrin Attia

Supervisor: Mr. Stéphane Aubin

June 2013 


\begin{abstract}
Personality provides a measure of how an individuals thinks, communicates with other people, reacts to different situations, deals with stress, sets goals, works to achieve those goals as well as how he/she analyzes information and handles situations. During the past century numerous researchers have attempted to identify the role of personality in several indicators of career success (such as job performance and satisfaction) and occupation matching. Psychological researchers have regrouped a number of major personality traits that can affect and predict the global performance of individuals. One of the most important models of personality that has generated a considerable amount of interest is the Big Five factor model or FFM which classifies human personality into five broad factors or dimensions; conscientiousness, neuroticism (or emotional stability), extraversion, openness to experience, and agreeableness. Our study based on this model as a framework for measuring personality and focuses on the three most powerful and influential factors (conscientiousness, extraversion, and emotional stability) that have been shown in previous studies to be most consistently correlated with global individuals performance (whether academic or job performance). Our purpose is to investigate whether there is a relationship between these super factors of personality and an individual's performance, in order to identify which personality trait(s) can play a role and to what extent they can predict in individuals' performance. Academic performance has been assessed in the present study as an example of global individual performance with the purpose of studying the possibility of predicting global individual performance including academic or job performance by personality traits. This is because personality traits which can predict and lead to academic success and achievement can also predict somewhat high job performance and success.
\end{abstract}

We assessed the academic performance through exam grades of two groups of 209 undergraduate students from two different academic courses: Marketing and Accounting in the Department of Administration Sciences at the University of Quebec at Chicoutimi. As well, we evaluated personality factors through a home-questionnaire of 
37 questions based on Big Five factors and some other personality traits not included in FFM such as locus of control, self-esteem and life and job (academic) satisfaction. We had addressed the questionnaire to the participants of each course in the beginning of the academic year and then they took several written examinations at the end of their academic year. We designed each item of the questionnaire to evaluate a particular factor of personality and each factor of personality was evaluated by a set of items or questions -9 to 10 questions in average- in the questionnaire. Then we conducted correlation and regression analyses to examine the correlation and the predictive ability of each item of the three selected factors and the exam grades of the participants.

Results showed conscientiousness to be the factor the most significantly and consistently correlated with grades in both courses. The correlations between this factor and exams grades ranged from $0.171(p<.05)$ to $0.389(p<.001)$, so we can say that scoring in conscientiousness is significantly related to academic performance in the sample.

The second selected factor, extraversion, showed significant negative correlation with grades of both courses. The correlations between this factor and grades of the participants ranged from $-0.175(p<.05)$ to $-.2,(p<.01)$. This means that extraversion level is significantly associated with academic achievement in the sample while we founded no significant correlation between grades and the third selected factor: emotional stability. We propose possible explanations for these findings, theoretical and practical implications as well as perspectives for future research.

The present study provides evidence supporting the validity of Big Five factors of personality as a potential tool for predicting individuals' global academic and job performance. 
Keywords: Personality, Big Five factors of personality, FFM, Individual Performance, Job Performance, Academic performance and achievement, Exam grades. 


\section{Thanks and appreciations}

I owe deep gratitude and gratefulness to my thesis advisor Professor Stephane Aubin, from the Department of Economic and Administration Sciences at the University of Quebec at Chicoutimi for his valuable and continuous support since I started studying for my masters and especially during my thesis research. I have been extremely lucky to have a supervisor who cared so much about my work and who responded to all my questions and queries immediately. He has always supported me not only by providing scientific orientation in the research but also morally and espertually all over the road to finish this thesis. The door of Prof. Stephane Aubin's office was always open whenever I ran to him with a trouble spot or I had a question about my research or writing. He has consistently offered me all the scientific resources and steered me in the right direction whenever I needed it. He helped me come up with the thesis topic and guided me over almost two years of development and during the most difficult times when writing this thesis. His wide knowledge and his logical way of thinking, his understanding, encouragement and helpful guidance have been of great value to me and have provided a good basis for the present thesis. Thank you, Prof. Stephane Aubin for giving me the confidence to explore my research interests and the guidance to avoid getting lost in my exploration.

I would like also to thank all my department members: Prof. Yves Lachance, Program Director, all my course professors: Brahim Meddeb, Julien Bousquet, Thierno Diallo, Erik Chamberland, and Jean Rouette for teaching and enriching me by scientific experience and technical support, MRS Lyne Desmeules, Program Secretary, for her cooperation, Mr. Claudio Zoccastello head of Registration at the University of Quebec at Chicoutimi for his cooperation and comprehension in solving all the registration problems that faced me as well as all those who have helped me directly or indirectly to succeed in this work. 
I offer also my deep loving thanks to my husband and best friend Ehab Elsharkawi and my sweetheart daughter Chantelle Elsharkawi for their presence physically and emotionally with me all during my study. They have lost a lot of my due towards them to my research abroad; without their encouragement and understanding it would have been impossible for me to succeed in this work. I am especially indebted to my beloved husband for his encouragement, understanding, patience, and his durable support which were undeniably the bedrock upon which my past three years of studying life has been has been built. Thank you my small beloved family for your unwavering love which gave me the power and the motive to succeed in this work.

Finally and most importantly, I pray and thank God infinitely for helping and allowing me to succeed in this work.

Nesrin Attia, Chicoutimi, June 2013 


\section{Dedication}

I want to dedicate this thesis to my beloved parents; my wonderful Mom Malak Nasry and my great Dad Moustafa Attia who brought me to life, raised me with love, teaching me responsibility and supporting me in all my pursuits. Without their encouragement and support I would not have started and succeeded in my master's study. Thank you my precious parents for your love, for your continuous support (both spiritually and materially), for giving me inspiration, for the unceasing prayers gifted to me with your cute and tender voice on phone calls which have enabled me to reach the present position in life.

I am forever indebted to my Mom who planted the seed of the idea to do research and her encouragement and prayers for attaining my goal. This great Mom who continues to teach, to educate, to support and to develop and who has been a source of encouragement and inspiration to me throughout my life, very special thanks for you my adored Mom for the myriad ways in which, throughout my life, you have actively supported me in my determination to find and realise my potential.

I thank God enormously for granting me such great parents.

Nesrin Attia,

Chicoutimi, June 2013 


\section{Table of Contents}

List of Tables............................................................................................................10

List of Figures...................................................................................................11

List of Shortcuts and Abbreviations.......................................................................12

Introduction and General Objectives...................................................................13

$>$ General objectives and Utilities of the research................................................14

Chapter 1: Big Five dimensions of personality and Five Factors Model of Personality (FFM)............................................................................................................19

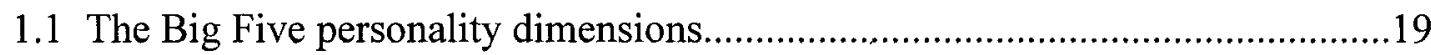

1.2. The emergence of the Five Factors Model of Personality....................................20

1.2.1. The theoretical background of the Five Factors Model of Personality........20

1.2.2. What is the Five Factors Model of Personality?..........................................21

1.3. How can the personality factors affect work and life behavior of individuals?..25

Chapter 2: How can the Big Five affect individual performance?............................28

2.1. The expected relationship between the Big Five and individual performance

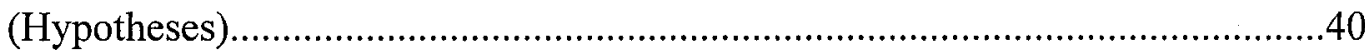

Chapter 3: Methodology.........................................................................................43

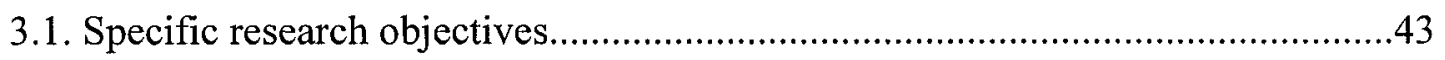

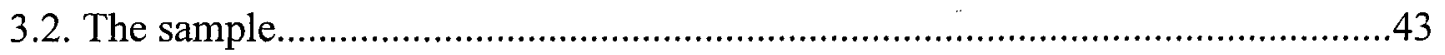

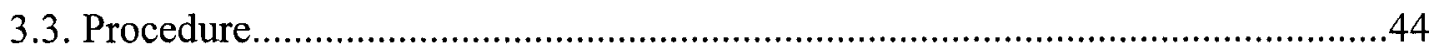

3.3.1. Methods of collecting the data..............................................................4

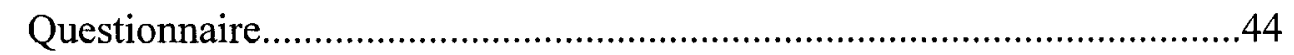

3.3.2. The variables of the research....................................................................50

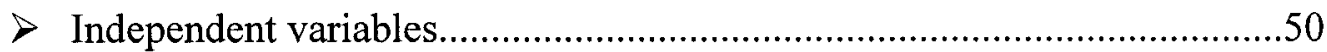

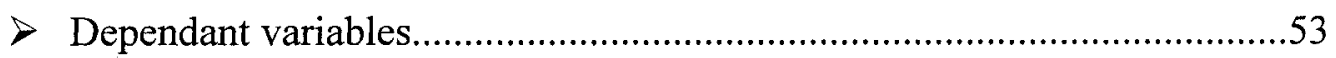

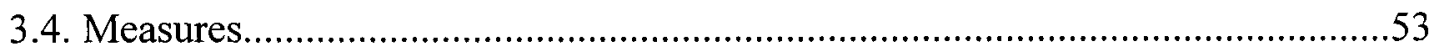

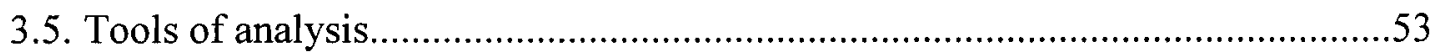

Chapter 4: Analysis...............................................................................................................55 


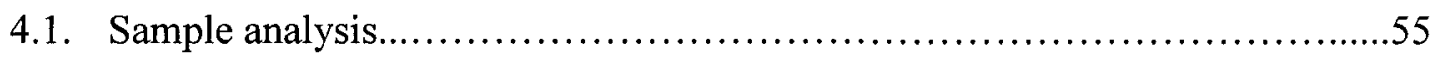

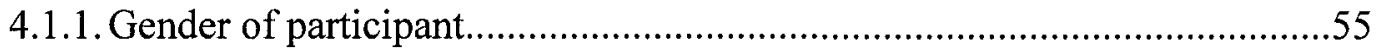

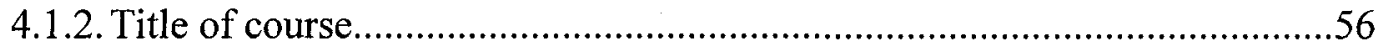

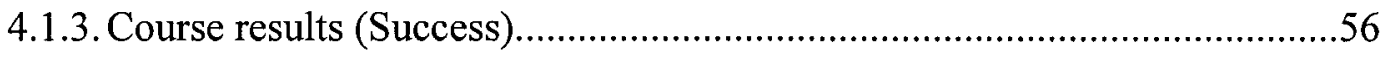

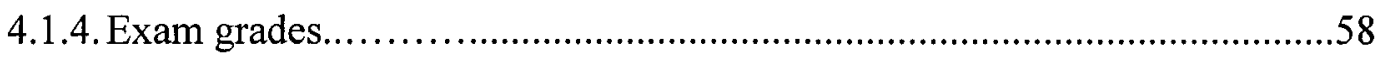

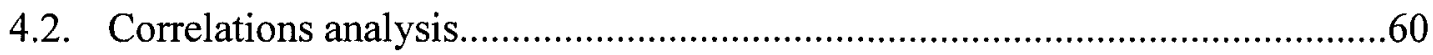

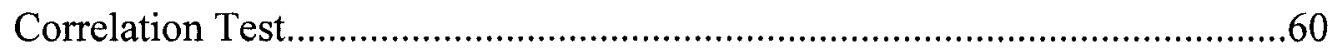

4.2.1. The correlation between conscientiousness and grades.........................61

4.2.2. The correlation between emotional stability and grades.........................63

4.2.3. The correlation between extraversion and grades of both of courses........65

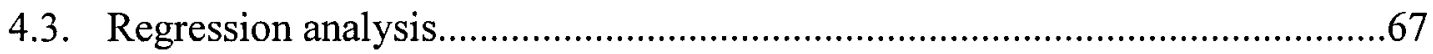

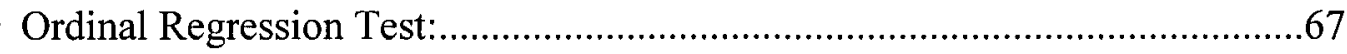

4.3.1. Conscientiousness/ grades regression analysis:.....................................67

4.3.2. Extraversion/exam grades regression analysis :...................................71

Chapter Five: Discussion and Conclusion...........................................................75

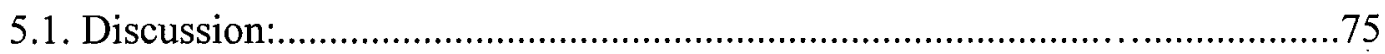

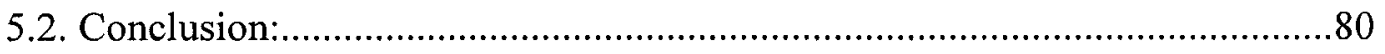

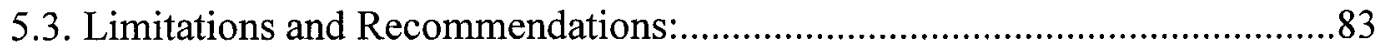

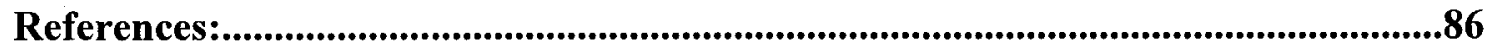

Appendix 1: The original questionnaire in French..............................................96 


\section{List of tables}

Table 1 : Questionnaire.......................................................45

Table 2 : Questionnaire's personality factors included in FFM................................47

Table 3 : Questionnaire's personality factors not included in FFM..........................48

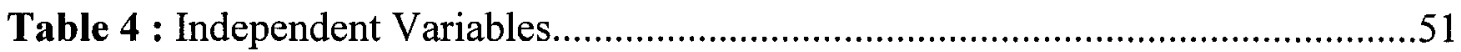

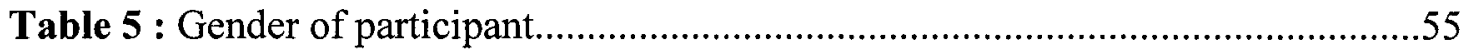

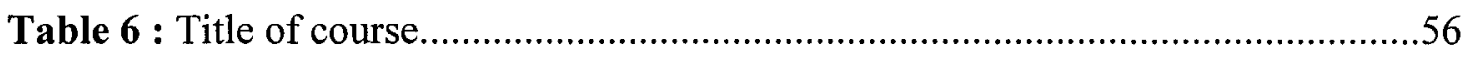

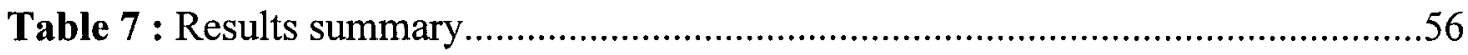

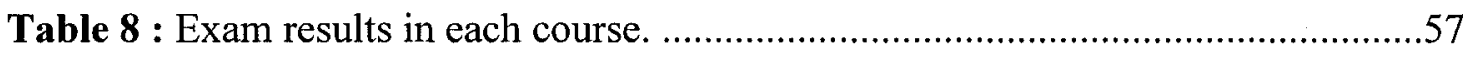

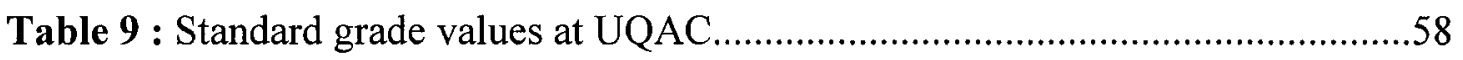

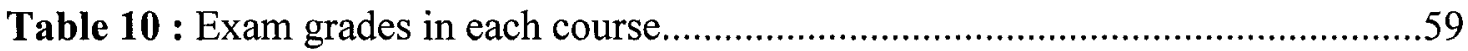

Table 11 : Correlations between conscientiousness and grades.............................62

Table 12 : Correlation between emotional stability and grades...............................64

Table 13 : Correlation between extraversion and grades......................................66

Table 14 : Conscientiousness Model Fitting Information table...............................68

Table 15 : Conscientiousness Goodness-Of-Fit table..........................................68

Table 16 : Conscientiousness Pseudo R-Square table......................................69

Table 17 : Conscientiousness Parameter Estimates table.......................................70

Table 18 : Extraversion Model Fitting Information table..........................................71

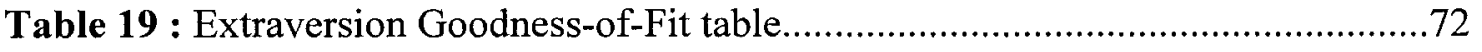

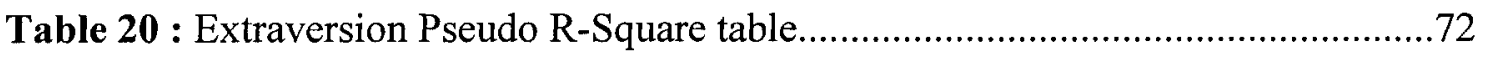

Table 21 : Extraversion Parameter Estimates table..................................................73 
Table 22 : The original questionnaire in French

\section{List of Figures}

Figure 1 : The Five Factors Model of Personality .................................................22

Figure 2: Evolution of the number of papers abstracts that linked personality with job

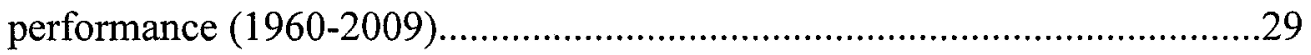

Figure 3 : Exam results in each course .............................................................58

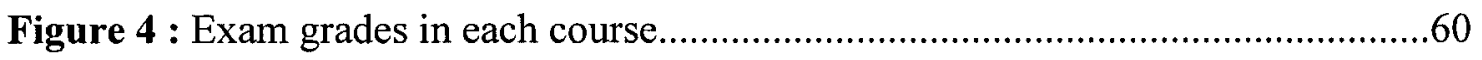




\section{List of shortcuts and abbreviations}

FFM : Five Factors Model of Personality.

Big Five : Big Five Factors of Personality.

Cons. : Conscientiousness.

Extr. : Extraversion.

Emotional Stab. : Emotional stability.

Emotional Int. : Emotional intelligence.

LOC : Locus of control.

Sense of Effic. : Sense of personal efficacy.

Life Satisf. : Life satisfaction.

Job Satisf. : Job satisfaction.

UQAC : University of Quebec at Chicoutimi (Université du Québec à Chicoutimi). 


\section{Introduction and general objectives}

The relationship between the personality and some indicators of job success (such as performance, satisfaction, salary, and status) has gained much attention in industrial psychology in the past century. The term 'job success' has been defined as 'the positive psychological and work-related outcomes accumulated as a result of one's work experiences" (Judge, Cable, Boudreau, \& Bretz, 1995; London \& Stumpf, 1982; Seibert et al., 1999). As one of the most important indicators of job success, the job performance of an employee could be defined as the individual quantity and quality accomplishment of specific job tasks or duties by using the available resources while respecting the organizational standards and the fixed time. As well, it describes the way he/she uses the available resources and time and the energy he/she spends to complete his/her work tasks. In summary, job performance describes how well an employee performs in his/her job. There fore, job performance reflects one's level of effectiveness in performing specific job tasks and duties and is measured with respect to a specific job (Greenhaus \& Parasuraman, 1993). Another important indicator of job success is job satisfaction. Locke (1976) has defined job satisfaction as "a positive emotional state resulting from an appraisal of one's job." Job satisfaction can be related to motivation, personal feelings and emotions towards the job and the whole organization, and to personality (traits of the personality of the employee). It is especially associated with job performance because high performance may lead to satisfaction and satisfaction can possibly lead to higher performance. In addition, individual performance is generally determined by five factors: the ability (the capability to accomplish the job tasks), the desire to do the job (the motivation), the personality accord (how much the individual's characteristics are suitable for the job?), the work environment, and the tools, materials, and information needed to do the job. 
Therefore, since personality can play an important role in an individual's performance in different jobs, the relationship between personality, job performance, and job satisfaction has been a frequently studied topic in industrial psychology in the past century. Over the past 40 years (from 1970 till 2009) the number of publications and researches studying the validity of some factors of personality as predictors of individual's performance has significantly increased. Further meta-analyses have affirmed the utility of using personality measures for personnel selecting purposes, helping the students to select the appropriate field with regard to their tendencies and characteristics, and for predicting overall individuals' performances which includes the academic performance (for students) and job performance (for employees). It is widely agreed that these personality traits could strongly affect the outcomes of performance such as the academic results and achievement of students or the quality and efficiency of employees' performance. As well, recent research by Ackerman and Heggestad (1997) suggested that individual difference variables such as personality, intelligence, and vocational interests can be used to explain not only the variance in academic performance, but also the processes by which traits influence examination outcomes.

\section{$>$ General Objectives and practical utilities of the research}

Since it is possible to associate particular traits of personality with individual performance, the main aim of our research is to inspect and investigate the possible relationship between specific variables of personality and the academic performance of two samples of undergraduate students (209 students) of two different academic courses: Marketing and Accounting in administration sciences department of UQAC. The aim is to establish a direct, clear, and precise link between the fundamental characteristics of personality and the academic performance of the participants, based on final exams results of those students of each course. If the relationship between particular factors of personality and the level of academic performance and achievement of the participants could be found, these factors can be used to predict work performance also because factors which can lead to high academic performance in an academic field can lead to high job performance in jobs related to this field. As well, the 
degree of academic performance and achievement of someone gives us clues about his expected performance in the occupations related to his education, therefore personality factors that predict academic performance can also possibly predict job performance. The requirements and the criteria of job success are different from those of academic and learning success and the conditions under which a student performs are different from those under which an employee performs. For example, a student with five courses per semester has a high study load as well as the stress of examinations that can affect their academic achievement. However, in general, academic performance can be an indicator of individual global performance. For example, conscientiousness, as an important factor of personality, has been found related positively to academic performance in many researches and meta-analyses which studied the effect of the personality on the academic performance and achievement. At the same time, this factor has been found in other studies and meta-analyses which studied the relationship between personality and job performance to be the factor of personality the most significantly correlated with work performance in all jobs. Therefore, since education changes an individual in such a way as to increase his/her capacity to perform job related tasks, measuring the academic performance or success can be considered an indirect measure of job performance.

If the relationship between individual performance and personality can be found, this relationship could be developed and the results could be used for predicting, promoting, and improving employees' performance, best employment selection, matching people to jobs, and for career and learning development purposes. For example, in order to make the best employee selection decisions, an organization has to identify the type of person it wants to hire by determining what personality traits are related to job success. That way, when the organization evaluates a candidate, it knows what it is looking for in this candidate to match with the job. For example, hiring an accountant means looking for someone who pays close attention to detail, and has good math skills. On the other hand hiring a salesperson, who will deal with the customers and represent the organization or the company, means looking for someone who is extraverted (sociable, outgoing, and talkative), agreeable (warm and enjoys helping people) and emotionally stable (calm 
with high stress tolerance). When the organization knows what kind of personality would be successful in a particular job, it can engage the right candidate (the right person in the right place).

Furthermore, for best hiring decisions, the organization has to integrate personality characteristics of the candidates with other subjective information such as recommendation letters, curriculum vitae, interviews, background checks and previous work experience. This additional data (beside the personality tests) provides supplementary details about a candidate's strengths and weaknesses. When these different techniques are used together, they can provide a full picture of a job candidate's - or an already engaged employee's - skills, abilities, values and ambition. This allows the organization to determine the human resources it needs for better personnel selecting as well as better management of its human resources.

In addition, Schneider's model shows that individuals select themselves into and out of organizations and that different types of people make different types of organizations. The implications of such research are that personality variables are important not only in determining who is seen as a leader, but also in assessing who is likely to fit in and remain with a particular firm. Both are important considerations in staffing organizations (Day, David V. and Silverman, Stanley B., 1989).

When the organization uses personality assessments to match an individual's skills to the job requirements, the person will learn more quickly, be more satisfied and successful, and stay longer in the job (www.Psychometrics.com). The economic benefits to the organization will include faster and cheaper recruiting, less turnover, and better job performance (using personality assessments to hire employees). For that reason, understanding the personality dimensions can help to explain both why different careers require different types of behaviors and why selecting certain answers in a job paper pencil test can qualify someone for certain jobs and disqualify them for the others. Human resources professionals usually use the Big Five personality dimensions to help 
place employees because these dimensions are considered to be the underlying traits that frame an individual's overall personality.

The validity of the Big Five dimensions of personality as variables related to the performance is always an underlying question because the results of the research and the meta-analyses concerning this subject were always opposed and contradictory. Therefore this research is an attempt to answer more clearly and subjectively the question of whether personality traits are valid predictors of general performance or whether they lack influence and are just poor predictors of performance.

In order to illustrate the main procedures and results of this research, this thesis will be separated into six chapters as following;

Chapter One will focus on describing the fundamental characteristics of personality which have been categorized in five broad dimensions of personality or the Big Five and will present a brief introduction to the historical emergence of the Big Five model of personality. It will conclude with a comparison of the effect of each dimension on the individual's behavior in life in general and in work in particular.

Chapter Two will discuss how the Big Five affect the individual performance of both students and employees (the effects of the Big Five on both the academic performance and the job performance) by presenting some of the previous reviews of literature which have studied and discussed the relationship between the Big Five and the individual performance (academic and job performance). It will conclude with our expectations of the effect of the Big Five on the academic performance of the participants in our research (the hypotheses which would be tested in this research).

Chapter Three will show the specific goals and steps of our analysis, the tools used to make predictions regarding personality and academic performance, a description of the students participating in the research and the variables that were tested. It will conclude with a description of the scientific methods used to analyze the data obtained. 
Chapter Four will focus on analyzing the collected data that includes personal characteristics and preferences of the participants and their academic performance, including examination marks and appreciations of their professors. It will conclude with the results produced from our various experimental analyses of the data.

Chapter Five will discuss the main results of the present study in order to affirm or deny the validity of the Big Five as indicators of performance and to determine which factor of personality is more correlated with high performance. Then it will conclude with a comparison between these results and those of previous studies in order to determine the strengths and the weaknesses of our results, and in order to explain the possible reasons for some results of our research. As well, it will shed light on some limitations of this study and make recommendations for future personality-individual performance researches.

At the end, since the organization must have tools to help them find the employee the best matched to the job, personality assessments are becoming a strong tool of choice; this is a good reason to study the correlation between personality differences and performance. 


\section{Chapter One \\ Big Five Dimensions of Personality \\ and Five Factors Model of Personality (FFM)}

\subsection{Big five personality dimensions}

Job performance can be affected by situational factors such as the characteristics of the job, the organization and co-workers (Hackman and Oldham, 1980; Strümpfer, Danana, Gouws and Viviers, 1998), and by dispositional factors which include personality characteristics, needs, attitudes, preferences and motives that result in a tendency to react to situations in a predetermined manner (House, Shane and Herrold, 1996). Job performance is also influenced by aptitude, need for achievement, self-regard, locus of control, affective temperament and the interaction between these constructs (Boshoff and Arnolds, 1995; Wright, Kacmar, McMahan and DeLeeuw, 1995). Therefore, it is widely agreed that personality variables can be significant predictors of individual performance when carefully matched with the appropriate occupation characteristics and organization.

Among the personality traits that have been frequently shown to be related to performance, the big five factors of personality or the Big Five: self-esteem, sense of personal efficacy, locus of control, personal satisfaction of performance and of life as a whole. Researchers believe that the differences in human personality and behavior can be mainly grouped in terms of the Big Five factors of personality which are identified as conscientiousness, neuroticism (vs. emotional stability), extraversion, openness to experience (intellect) and agreeableness. These five broad dimensions describe the human personality according to the differences between individuals in characteristics; aptitudes, intellect, and personal interests and preferences. The Big Five have been studied and validated by many different psychologists in different cultures and 
traditions (Norman, 1963; McCrae and Costa, 1987; Brand and Egan, 1989; Goldman, 1990; Sinclair, 1992), and they were the base of most later personality questionnaires.

Personality factors or dimensions are based on two fundamental assumptions. Firstly, they are stable over time even though an individual's behavior may vary from one situation or condition to another; there is a core consistency that defines the individual's nature. For example, it may be expected that a student who has been noted as a worrier would be unusually disturbed and worried in different contexts such as: examinations, social occasions, and group discussions. Secondly, it is generally believed that personality dimensions are strongly related to behavior; they directly influence and explain behavior (they justify individuals responses and reactions to different situations) (Matthews et al., 2003). Also, research has shown that the Big Five have a genetic basis which remains stable throughout an individual's life even if reactions can change occasionally depending on situations and circumstances (Digman, 1989) and that they are probably inherited (Jang, Livesley and Vernon, 1996).

The Big Five have been covered in many studies and meta-analysis in different cultures and countries in order to create a personality-performance relationship. The wide range of results have shown that different dimensions of personality are related to individual performance in various occupations (Rosse, Stecher, Mille and Levin, 1998; Wright et al., Rosse et al., 1995) and to job satisfaction (Connolly and Viswesvaran, 2000; Hart, 1999; Judge, Higgins, Thoresen and Barrick, 1999).

\subsection{The emergence of the Five Factors Model of personality}

\subsubsection{The theoretical background of the Five Factors Model of personality (theoretical perspectives)}

Allport and Odbert (1936) were the first researchers identify a set of words describing personality characteristics in the English language. With a conclusion of 4,500 words, it was the primary starting point of language-based personality trait research for the last 
sixty years (Howard and Howard, 2004). Later, Cattell (1946) scientifically drived 16 personality traits using factor-analytic and related statistical procedures, suggesting that these factors represent the major dimensions for explaining the differences in human personality (Liebert and Spiegler, 1994). However, Fiske (1949) suggested that five, not sixteen, factors accounted for the variance in personality trait descriptors. Although other theories of personality were based on psychological theory, it can be clearly seen from the development of the Five Factors Model that it is mainly empirically based, that it was founded in factor analysis. Using this process of factorial analysis, Tupes and Christal (1961) originated the theory of five underlying factors which are the basis of personality measurement. This theory was refined by Norman (1963), Eysenck (1967), and Costa and McCrae (1992) later developed a solid basis for the Five Factors Model. Since that time, FFM has received wide notice in the field of psychology. Many studies have confirmed that the Big Five factors emerge quite consistently in different populations of individuals, including children, college students, older adults, and speakers of different languages (Costa and McCrae, 2004; McCrae et. al., 2004; Aluja et. al., 2005).

\subsubsection{What is the Five Factors Model of personality?}

The Five Factors Model of personality is a hierarchical model of personality based on the previous five broad factors or dimensions: conscientiousness, neuroticism, extraversion, openness to experience and agreeableness to classify and distinguish an individual's character. It was refined by Goldberg (1990) and developed by Costa and McCrae (1985) into the widely used 300-item Neo-Personality Inventory Revised (NEO-PI-R). Scoring on these factors provides a complete picture of a person's personality. The five broad factors of FFM are illustrated in the following figure: 


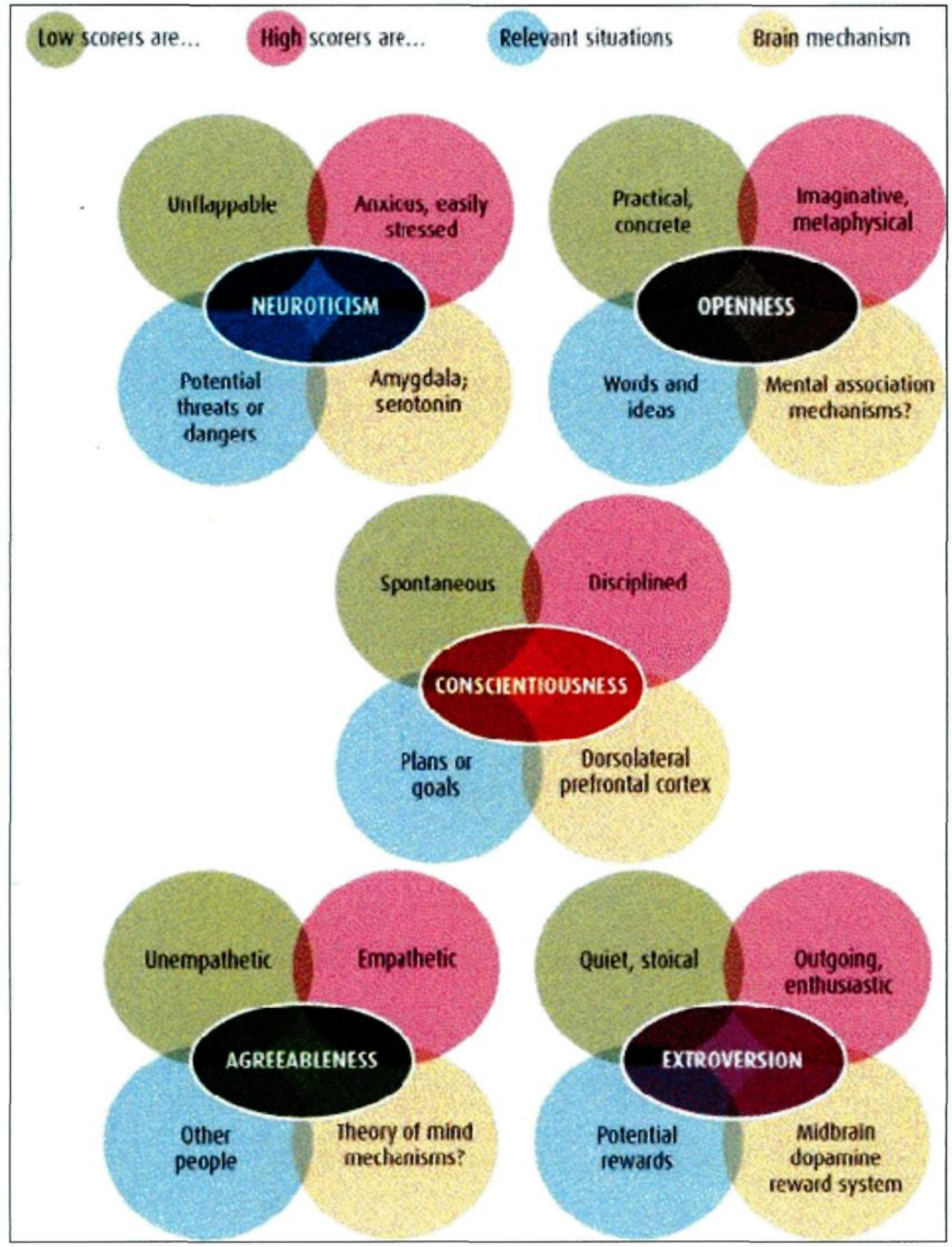

Figure 1: Five Factors Model of personality

As Figure 1 illustrate, the Five Factors Model of personality contains a set of interacting and intercorrelated traits developed in five broad factors or dimensions (the Big Five), which shape and influence individuals' tendencies and behaviors. 
The five factors or dimensions of the Five Factors Model of personality (the Big Five) consist of:

\section{Conscientiousness}

This factor describes how much a person is self-disciplined, dutiful, hard-working, organized, and well-planned. Barrick and Mount (1993) defined this factor as selfcontrol and the active process of planning, organizing, and carrying out tasks. This dimension has great effect on a person's values and behavior. Conscientious people are concerned about doing their duties and making sure that tasks get done perfectly. They are responsible, well-organized, focused, determined, strong-willed, and dependable. On the negative side, a high conscientiousness degree may cause annoying fastidiousness, compulsive neatness or workaholic behavior. Unconscientious individuals are more flexible and spontaneous. Low scorers may not necessarily lack moral principles, but they are less exacting in applying them. Very low-scoring conscientiousness people are unreliable, disorganized, and easily distracted (Rothman and Coetzer, 2003).

\section{Neuroticism (vs emotional stability):}

As opposed to emotional stability, this factor indicates that a person's personality is characterized by anxiety, nervousness, and high irritability. Neurotic people have high levels of negative emotions such as anxiety, worry, bad temper, depression and guilt. An elevated neuroticism score points out that the person tends to have a nervous and irritable character, to be less able to control anxiety and to deal poorly with stress. A highly neurotic person is emotionally reactive and easily inflamed. He can't usually recover from depression and shocks easily. He is always stressed, nervous, and subject to depression. A low neuroticism score indicates that the person is emotionally stable. These people are usually calm and relaxed, have high control of their anxiety, are not prone to getting nervous and can deal adequately with stressful situations. 


\section{Extraversion}

This factor is characterised by sociability. Extraverted people are very sociable, they like to attend parties and other social events and they have many friends. They have great ability to talk and to express emotions and they can communicate easily with people. On the other hand, introverted people often prefer to spend much time alone. They are conservative and don't easily integrate with other people. Usually, they don't like to attend parties and events and when they do they stay in a corner in the party. Extraversion is characterized by positive feelings and expression and this can have positive effects on work and on life in whole. Many researchers affirm that extraversion is a valid positive predictor of work performance and success in jobs which involve social interaction, such as sales personnel and managers (Barrick and Mount, 1991; Bing and Lounsbury, 2000; Lowery and Krilowicz, 1994; Vinchur et al., 1998).

\section{Openness to Experience}

This factor indicates how much someone is open to new experiences and ideas. An open person always seeks to learn new experiences and to innovate new ideas. $\mathrm{He} / \mathrm{she}$ has active mind and imagination and he/she has great curiosity and attentiveness to have new knowledge and skills. People who score high on this dimension are artistically sensitive, curious, creative, and they are ready to learn new skills. Their lives are experientially richer than those with low scoring. On the other hand, people scoring low on openness tend to be conservative and cautious in behavior. They prefer the familiar to the innovative.

\section{Agreeableness}

This factor describes whether someone is amiable or agreeable to other people. An agreeable person has a pleasant character, is fundamentally kind, trustful, cooperative, warm, and ready to help and support others. A disagreeable person is cold, unpleasant, uncooperative and sometime aggressive. He/she cares much more about climbing toward high positions without regard to other considerations and other people. 
These Big Five dimensions represent wide areas of personality. Research has demonstrated that these groups of traits assembled in each dimension of personality tend to be consistent and to occur together in many people. For example, although extraverted people are sociable and talkative, it isn't necessary that these two traits occur together all the time. Personality is complex and varied, and each person may respond to situations through all these five dimensions.

\subsection{How can the personality factors affect work and life behavior of individuals?}

Personality produces individual attitudes, so in order to understand the behavior of someone in an organization or the reasons behind his/her responses to work or life situations, it will be helpful to know about his/her personality. Personality evaluation provides predictions of how an individual communicates and works with others, reacts to changes and handles stress. These differences between individuals' personalities can make them more or less cooperative with their supervisors and colleagues, less efficient in some jobs and more productive in others. Therefore, these differences between individuals affect considerably their efficiency in doing their work, their behavior in life, as well as the degree of their satisfaction in both their lives and their jobs. For that reason, the Big Five have important implications in work and life as follows.

1. Conscientiousness: Conscientious people live longer because they pay attention to everything, they tend to take better care of themselves (better nutrition, more exercise, etc.), and engage in fewer risky activities. Everything is organized for conscientious people, including their lifestyle and work manner. It seems that conscientious employees have more problems to adapt to because they are so ordered and punctual. They are very productive and comfortable with familiar and pre-planned tasks. As well, they have sometimes more troubles in complex learning tasks because they pay more attention to detail and accuracy than to learning. 
2. Neuroticism (vs emotional stability): Emotionally stable people are more productive in their jobs and happier in life because emotional stability is related to life and job satisfaction and low stress levels. Therefore, they live more calmly and comfortably and with less health troubles. Low emotionally stable people (neurotic people) can make fast and perhaps wrong decisions in a bad mood. These decisions can be important and affect their jobs and lives. At work, being calm, secure, and nonirritable results in effective interaction with workmates and clients (Barrick, Mount and Judge, 2001).

3. Extraversion: Extraverted people tend to be happier in their jobs and their lives as a whole than introverted people because they talk more, can express their emotions more, lough more and can present themselves and their personal skills better than entroverted people. They are sociable and have many friends. They are active, talkative, and it is rare to see an extraverted person silent or reserved. On the other hand, they can be more spontaneous and a subject to have troubles in work or in their studies. For example, extroverts are more likely to be absent from work or academic institutions and to engage in risky adventures or other impulsive or sensation-seeking situations.

4. Openness to experience: People with a high score in openness to experience are more creative, more productive and efficient in art and science, and they tend to be less rules-constrained. They are more able to deal with organizational changes and more adaptable to changing circumstances. Because of their high desire and capacity to acquire new experiences and skills, open people are active and curious during training and ask more questions which enable them to learn efficiently.

5. Agreeableness: Agreeable people are warm and cooperative as part of a work team and outside the organization. They are perfect work team members. They live more happily because when people look for life partners, friends, or organizational team members, agreeable individuals are often their first choice. Agreeable employees or students are most productive in jobs or situations that involve interpersonal cooperation, 
such as helping, cooperating, and nurturing others. In contrast, disagreeable people are uncooperative, inflexible, and uncaring. Disagreeable students or employees are likely to have low ratings on teamwork. (Barrick, Mount and Judge, 2001). 


\section{Chapter Two \\ How can the Big Five affect individual performance?}

\section{(Literature review)}

Job performance can be influenced by two fundamental groups of factors;

- Organizational and situational factors which pertain to the job and the organisation as a whole, such as the nature, characteristics, and requirements of the job, the co-workers and workmates, the managerial system of the organization (including human resources management), and the organization's general purposes and aspirations.

- Dispositional and personal factors or individual factors such as personality characteristics, needs, tendencies, preferences, attitudes, motives, and personal goals.

The effect of personality as an influential factor on individuals' performance has been covered throughout the present century in many studies and meta-analyses across different countries and cultures in order to understand how personality factors (especially the Big Five) can affect individuals' academic or job performance in different jobs or learning fields. Most differences between the results of these studies and meta-analyses were related to which factors of the Big Five are the most significant and influential and whether these factors affect the performance negatively or positively. The number of studies and articles which discuss the use of personality factors to predict individuals' work performance increased significantly from 1995 till today because of the growing interest in this subject (personality and individual perofrmance) in human resources management field. From 1970 till 1994, the number of publications related to this subject was about 100. Since 1995 till 1999, the number of publications has exceeded 100. Since 2000 till 2009, the number of these publications has exceeded 400 papers and studies (APA PsycNet "American Psychological 
Association"). The following figure illustrates the evolution of the number of these papers and studies.

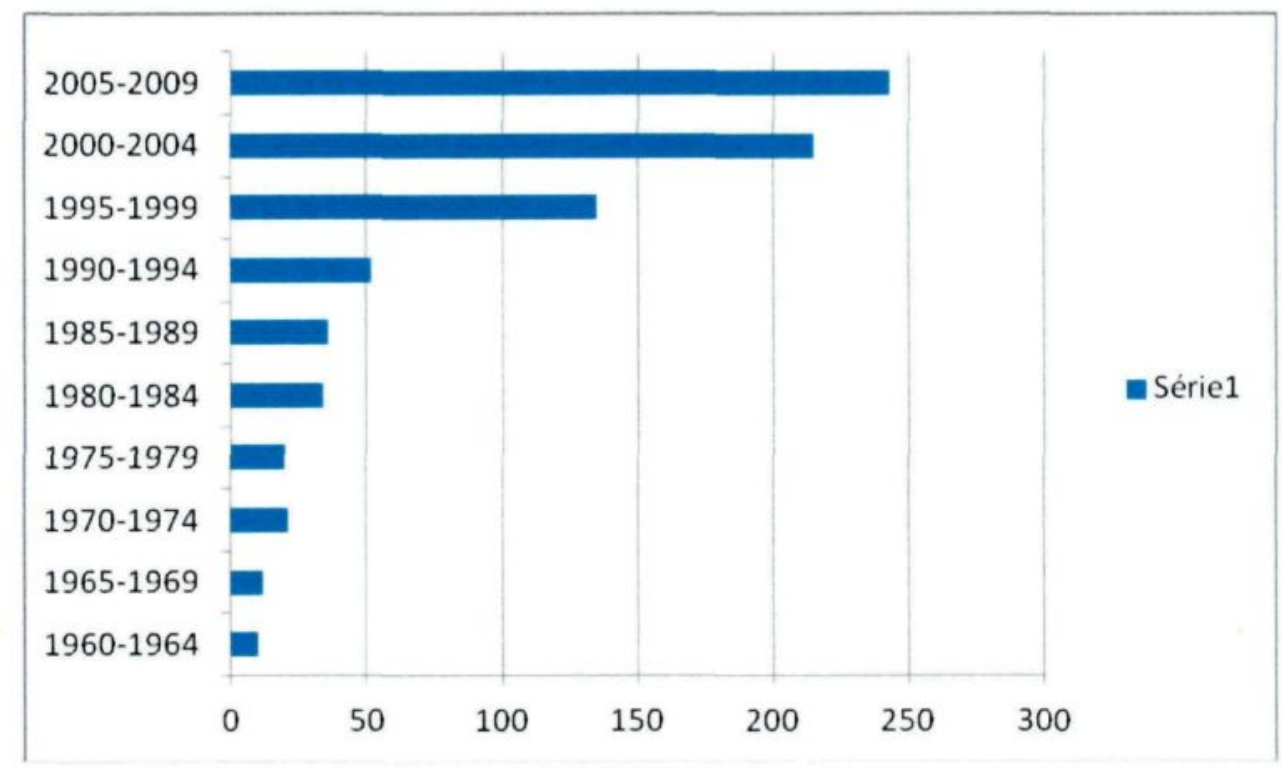

Figure 2: Evolution of the number of papers abstracts that linked personality with job performance (1960-2009)

These data are the result of a research in APA PsycNet (American Psychological Association) that identifies the number of papers published in specialized journals in which the words personality and job performance are mentioned in the abstracts.

Traditionally, industrial psychologists have studied the use of personality measures in predicting individual performance in general (including academic and job performance). The studies that have investigated the relationship between personality and job performance in particular during the present century came in two distinct phases (Barrick, Mount and Judge, 2001).

The first phase (the primary phase) lasted a relatively long time and includes studies conducted from the early 1900 s to the mid-1980s. These first studies investigated the relationships between individual scales from numerous personality inventories to various aspects of job performance. The overall conclusion of these studies was that personality and job performance were not related in any meaningful way across traits 
and across situations. There are some possible explanations for this primary conclusion. Firstly, no classification system was used to assemble the thousands of personality traits into a smaller number of groups. Secondly, there was lack of clarity about the measured traits. For example, in some cases researchers were using the same name to refer to traits with different meanings and in others were using different names for traits with the same meaning. Finally, the literature reviews at this time were largely narrative rather than quantitative, and did not correct for study artifacts that led to downwardly biased validity estimates. These problems made it difficult to identify consistent relationships between personality traits and criteria and consequently, little advancement was made in understanding personality performance relationships (Barrick, Mount and Judge 2001).

The second phase (the recent phase) covers the period from the mid-1980s to the present day. It is characterized by the use of the FFM (Five Factor Model) to classify personality scales. Most primary studies conducted since 1990 have used instruments that assess personality traits at the FFM level, or have used the FFM to classify individuals' scales from personality inventories. Also the recent phase is characterized by the use of meta-analytic methods to summarize results quantitatively across studies (Barrick, Mount, and Judge 2001).

Although, The FFM or the Big Five was the measure the most frequently used in the studies and meta-analyses carried out in the past few years. There was a conservative trend in academic psychology arguing that personality measures or the Big Five lack validity, are easily faked, and are generally unsuitable for decisions about job performance. The disbelief regarding the usefulness of personality measurement for predicting performance reached its peak during the 1960s with the publication of Mischel's book (Personality and Assessment, 1968). He declared that there is no proof that personality is constant across all situations and he thought that personality measures explain only a slight amount of variance in performance. Nevertheless, the validity of the Big Five in predicting and explaining individual performance in various jobs and learning fields has found common support and has been approved in many studies and 
meta-analyses. For example, Hough et al., (1990), Tett, Jackson, and Rothstein (1991) Barrick \& Mount (1991) Goldberg (1993) Wright et al. (1995) Rosse, Stecher, Miller and Levin (1998) Vinchur, Schippmann, Sweizer, and Roth (1998) Barrick, Mount, and Judge (2001) showed that Big Five factors are related in different ways to job performance. Other evidence (Thoreson et al., 2004) showed that the Big Five are valid predictors of diverse job criteria.

Salgado (1997) conducted a meta-analysis using 36 validity studies carried out in Europe of the relationship between the Big Five and three criteria of job performance (supervisors' ratings, training ratings and personnel data) in five occupational groups. He found that 1) conscientiousness and emotional stability are significant predictors for all performance criteria and for most occupational groups, 2) extraversion predicted manager and police performance and 3) openness to experience predicted police and skilled labour performance. As well, results of the meta-analysis conducted by Barrick, Mount, and Judge (2001) supported the previous findings that conscientiousness is a valid predictor across performance measures in all occupations studied. Emotional stability was also found in this meta-analysis to be a generalized predictor when overall work performance was the criterion. But this relationship to specific performance criteria and occupations was less consistent than was conscientiousness. Also they found that extraversion, openness, and agreeableness do not predict overall work performance criterion, but they do predict success in specific occupations criteria such as high training proficiency and teamwork. It was also expected in this meta-analysis that higher scores in extraversion factor would predict successful work performance in two occupations, sales and managerial jobs.

Rothman and Coetzer (2003) in their study of 159 employees of a pharmaceutical company found that conscientiousness, emotional stability, extraversion, and openness to experiences were related to task performance and creativity. Emotional stability, openness to experience, and agreeableness explained $28 \%$ of the variance in the participants' management performance. Also, the results of the studies and metaanalyses conducted by Schneider (1999), De Fruyt and Mervielde (1999), Tokar and 
Subich (1997), and Vinchur et al. (1998) affirmed that extraversion and conscientiousness predict job performance in different occupations.

Stewart and Carson (1995) investigated the relationship between the Big Five and the work performance of a sample of hotel employees. The results showed that conscientiousness, extraversion, and agreeableness were related to three performance criteria (dependability, citizenship, and work output) as follows: conscientiousness and agreeableness were positively related to dependability and work output whereas extraversion was negatively related to citizenship and dependability.

In addition, Hayes et al. (1994) found in their study on a sample of automobile machine operators that conscientiousness (positively) and openness to experience and extraversion (negatively) were related to supervisors' ratings of particular performance measures and global work efficiency, but another later study by Krilowicz and Lowerey (1996) found significant positive associations between operator productivity of a sample of sewing machine operators and a number of personality qualities very close to both of conscientiousness and extraversion.

Regarding academic performance as another sort of individual performance, several studies and meta-analyses have affirmed the validity of some factors of the Big Five as predictors of academic performance and achievement in different educational levels and field. In a large number of meta-analyses, research has shown that four of the Big Five factors are frequently related to general academic performance and particularly to examination performance and grades as an important measure of academic achievement. These factors are conscientiousness and openness to experience (positively), neuroticism and extraversion (negatively particularly in examination performance). For example; using the examination results of 274 undergraduate students over three academic years as a measure of academic performance and Big Five factors besides some other primary or subfacets traits (such as; dutifulness, achievement striving, self discipline, etc.), Chamorro-Premuzic and Furnham (2003a) found that Big Five traits especially, conscientiousness (positively) and extraversion and neuroticism 
(negatively) were significantly correlated with examinations grades, accounting for around $15 \%$ of the variance. Also the results showed significant correlations between the subfacets traits, notably dutifulness and striving for achievement (positively) and anxiety and activity (negatively), and they were found to explain about $30 \%$ of the variance in examinations results.

In another study on the Big Five and exam marks and final year projects of 70 undergraduate students throughout three academic years, Chamorro-Premuzic and Furnham (2003b) found that the Big Five, particularly neuroticism and conscientiousness were found to predict overall final exams marks over and above several academic predictors such as openness to experience and extraversion. These accounted for more than $10 \%$ of unique variance in overall exam marks with the conclusion that neuroticism may harm or hinder academic performance, while conscientiousness can lead to higher academic achievement.

Using multiple and specific academic performance criteria of 133 students in a college of higher learning in the Netherlands, Kappe and Flier (2010) found that Big Five were correlated with grades on five different learning criteria: classroom lectures, skills training, team projects, on-the-job training, and a written thesis. This indicates that conscientiousness is an important indicator for performance higher education, regardless which performance criteria was used, and that neuroticism is positively related to performance in less stressful assessment conditions.

Of the Big Five factors, conscientiousness has been shown to be the one the most consistently associated with all academic performance criteria. Many studies have affirmed this association such as Wolf and Johnson (1995), who asserted that conscientiousness and self control are the best predictors of college performance and undergraduate education (Goff and Ackerman, 1992; Chamorro-Premuzic and Furnham, 2003a, 2003b; O'Conner and Paunonen, 2007; Kappe and Flier, 2010) and postgraduate education (Hirschbarg and Itkin, 1978). 
Almost all the studies and meta-analyses assert that conscientiousness is a positive predictor for individual performance across a wide range of job positions and learning degrees, which means that people who have been assessed to be higher on conscientiousness tend to perform better at work. However, Tett (1998) emphasized some reservations and cautions about accepting this conclusion as a rule or a base. $\mathrm{He}$ presented two kinds of work circumstances where conscientiousness may actually impede the job performance.

Firstly, being conscientious may result in less productivity in some situations where tasks need more time to complete, then fewer tasks can be completed in the allotted time. For example; managers are sometimes required to make quick decisions even when they do not have all the necessary information. In this situation, being highly conscientiousness can be unhelpful concerning the speed at which decision has to be made.

For the second example, Tett (1998) mentioned that conscientious individuals stick to rules and procedures. In certain occupations or specializations, strictly complying with rules and procedures may affect creativity and innovation. As well, it can affect negatively the individuals' ability to develop new ideas and innovations.

Concerning the other Big Five factors, it has been shown in several studies that more stable individuals tend to score higher on ability tests (possibly because they tend to be less negatively affected by anxiety and stress (Furnham and Mitchelle, 1991; Zeinder, 1995; Zeinder and Matthews, 2000). Other studies found that more stable students have also higher academic performance and achievement in post secondary and university education (Cattell and Kline, 1977; Goh and Moore, 1978; Sanchez-Marin, RejanoInfante and Rodriguez-Troyano, 2001; Lathey, 1991). The negative relationship between academic achievement (particularly examinations) and neuroticism that have been found in several previous studies and meta-analyses has been explained in terms of high stress and anxiety of neurotic students under test or examination conditions (Zeinder and Matthews, 2000). Such traits were found to negatively affect the academic 
performance in a more general way not just through exam performance such as grade point averages (GPA) in post-secondary education (De Fruyt and Mervielde, 1996; Chamorro-Premuzic and Furnham, 2003a; Chamorro-Premuzic and Furnham, 2003b) and research and thesis performance (Chamorro-Premuzic and Furnham, 2003b).An earlier research of Eysenck (1967) suggested that neuroticism and extraversion are theoretically and virtually associated with mental ability, particularly in mental speed which means low neuroticism, high extraversion and high intelligence can result in high mental speed.

Despite the common belief in the negative relationship between neuroticism and academic performance, earlier study of Eysenck and Eysenck (1985) suggested a possible uncertainty about the negative relation between neuroticism (particularly anxiety) and academic success and achievement. This suggests that the positive motivational effects of anxiety may be higher in elevated intelligent students because they face less difficulty in their studying, and neuroticism may be a positive predictor in bright students but a negative predictor in less talented students.

Extraversion factor has been shown in several early and recent studies with wide agreement to be negatively related to academic performance and achievement. For example, an early study of Entwistle and Entwistle (1970) discussed the relationship between extraversion and academic performance with the conclusion that less extraverted students have greater academic achievement because they have greater ability to learn, greater concentration while studying, and better study habits. Recent studies of Sanchez-Marin, Rejano-Infante, and Rodriguez-Troyano (2001) found also that extraverted students perform lower in academic settings because of their recklessness, high sociability, and impulsiveness. Further, Rolfhus and Ackerman (1999) found extraversion to be negatively related to several knowledge tests, they suggested that these relationships may be related to differences in time spent studying and reading between introverts and extraverts (introverted spend more time studying and reading when extraverted spend more time with friends and in events). 
Despite the common agreement of the negative relationship between extraversion and learning achievement and acknowledgment, Furnham, Forde and Cotter (1998a, 1998b) found that extraverted people perform significantly better than introverts on a measure of logical analysis. Therefore, we can't say that these people (extraverted people) have less intelligence or mental ability because it has been shown that they are more clever and performant in specialities and jobs that match their abilities in talking, sociability and promptitude and less performant in specialities and academic branches that require long hours of studies or reading. Although it has been shown widely that extroverted students perform less well on academic performance criteria (because they don't like to spend much time studying or reading but they prefer to socialize), this factor has been shown in other studies to be related positively to job performance and success in jobs that involve interpersonal interactions such as sales representative, supervisor, manager or animator (Barrick and Mount, 1991; Mount et al., 1998; Bing and Lounsbury, 2000; Barrick, Mount and Judge, 2001). Hence, it is difficult to find a constant form or pattern for the relationship between extraversion and intelligence that is weaker or more contextual and conditional than neuroticism. Similarly, Furnham et al. (1998) suggested that the relationship between extraversion, intelligence, and mental ability is affected by the type of intelligence test used. For example, extraverted people prefer timed tests, while introverted people prefer longer or non-timed test.

Openness to experience has also been associated with academic performance and success in different education levels, it has been positively associated with performance and success in school education (Shuerger and Kuma, 1987) as well as post-secondary level (which includes both of undergraduate and post graduate level of university education) (Hirschberg and Itkin, 1978; Blickle, 1996; De Fruyt and Mervielde, 1996). O'Connor and Paunonen, 2007) found that post-secondary academic performance was positively associated with openness to experience and some of its narrow personality traits, and negatively associated with extraversion and some of its constituent personality traits. 
Also, openness to experience has been shown to be a positive predictor for GPA (Rothstein et. al., 1994; Gray and Watson, 2002; Farsides and Woodfield, 2003). It predicted final course grades (Lounsbury et al. 2003), class participation grades (Rothstein et. al., 1994) and was related positively to success in training (Barrick and Mount, 1991; Vinchur et al., 1998), because openness to experience is characterized by curiosity and the tendency for looking for and discovering new experiences and to perceive and innovate new ideas.

These previous associations have often been interpreted by the belief that this factor is normally correlated with intelligence. Barrick and Mount (1991) suggested another possible reason about openness to experiences frequently correlated with academic achievement is that individuals who score high on this dimension (e.g., intelligent, curious, broad-minded, and cultured) are more likely to have a positive desire and behavior toward learning and experiences in general. They found in their meta-analysis that openness to experience is a valid predictor of one of the job criterion categories (training proficiency), but not for the other two, job proficiency or personnel data. According to Barrick and Mount, openness to experience may identify which individuals are "training ready" (those who are most willing to engage in learning experiences) and consequently, this factor may be useful in identifying those who are most likely to benefit from training programs. Thus, openness to experiences is actually measuring ability to learn as well as motivation to learn (Barrick and Mount 1991).

In contrast, recent studies (e.g. Wolfe and Johnson, 1995; Busato et al., 2000; Chamorro-Premuzic and Furnham, 2003) failed to associate significant relations between Openness to Experience and academic achievement. Thus, openness to experience may be related to higher intelligence, but not constantly with academic attainment. Further, it is possible that openness may have positive outcomes in academic performance when artistic, creative, and imaginative intervention is required, but not in other criteria in which systematic, organized, and dutiful performance is required (Chamorro-Premuzic and Furnham, 2003). On the other hand, the results of the meta-analysis of Johnson (1997), based mainly on FFM and multi-criteria of social 
performance, showed that employees with lower scores on openness to experience were more successful than those with high openness to experience scores. As well, Tett et al. (1991) failed to reveal significant relations between openness and job performance in their study, declaring that openness to experience is an invalid predictor of job performance. These conflicting results of the validity of openness to experience as a predictor of job performance can be justified since different professions or occupations have different requirements.

Regarding the last factor of FFM, agreeableness was found in few studies to be weakly correlated with job and academic performance and success. For example, Tett et al. (1991) asserted that agreeableness is a significant predictor of job performance. On the whole, agreeableness was found to lead to success in certain situations and occupations, such as customer service and in teamwork because of the helpful and cooperative nature of agreeable people (Judge et al., 1999). Barrick et al. (1998) and Mount et al. (1998) argued that agreeableness appears to have high positive effect on job performance in occupations or situations where cooperating, helping, and nurturing others is essential., Agreeableness, then, can be the best personality predictor in those jobs. Also, agreeableness was found to be related to training success (Salgado 1997).

Concerning academic performance, agreeableness has not been found to have significant correlation with academic performance or achievement. Because being helpful, nice, and gentle does not means being a high performer or in other words, does not lead to high academic performance. This factor can be important and helpful in work performance especially in jobs dealing directly with the public which requires that the representative be agreeable, cooperative, and helpful. For example, in sales, which require dealing with customers, this factor is strongly correlated with high performance. In academic performance, this factor can have correlation with high performance in studying groups where the cooperation between group members is required in order to complete tasks rapidly and efficiently. In other learning performances or practice (in examination marks for example), this factor does not have a significant relation with academic success or achievement. This is in contrast with neuroticism because 
neuroticism has a negative correlation with performance in stressful situations (for example, in examinations or in seminars). Under stress, a neurotic student performs beneath his capacity because his neurotic nature negatively affects his concentration in examination or presentation situations. This fact can be generalized in job performance also because a neurotic employee performs less efficiently in stressful situations (such as under high loads of work or in conferences) than in usual work situations. Furthermore, (Ackerman and Hagesstad, 1997; Zeinder and Matthews, 2000) found that agreeableness is unrelated to intellectual ability. Therefore this factor may not have an effect on academic performance.

In the same way, Chamorro and Furnham (2003) found in their study on Big Five and academic examination performance that agreeableness was not significantly related to examination grades, when other personality super traits such as conscientiousness (positively) and neuroticism and extraversion (negatively) were significantly correlated with examination grades and were found to account for $15 \%$ of the variance. De Raad and Schouwenberg (1996) have suggested that agreeableness alone can't be directly related to performance, but in combination with conscientiousness, can be part of character education. However, this factor involves important qualities for working in groups, and can play a role in the evaluations of behaviors in class more than written work (Rothstein et al., 1994). Therefore, the correlations given in the literature concerning this factor were often insignificant.

In conclusion, many researchers have proved the ability of some individual differences such as personality traits (particularly FFM) to predict and explain global individual's performance including academic or job performance. Of the Big Five, the traits found closest to academic performance and success were conscientiousness and openness to experience, the farthest was agreeableness, with extraversion and neuroticism in the middle depending on the situation or criteria. 


\subsection{The expected relationship between Big Five factors and individual performance (Hypotheses):}

Based on the results of the previous studies which investigated the relationship between personality and global individuals' performance and the effect of each factor of personality in the academic performance in particular, we can expect some effects of each of the Big Five factors on the academic performance and success.

Since conscientious individuals are well organized, dutiful, hardworking, efficient, respectful, determined and persistent - essential qualities for accomplishing all academic tasks in all academic branches, and since conscientiousness was the factor most associated with academic achievement in the previous studies and meta-analysis, Therefore:

Hypothesis 1: We expect in our study that conscientiousness will be positively and significantly related to academic success of the participants in both of academic courses (marketing and accounting). In other words, high conscientiousness students will have higher grades comparing with low conscientiousness students.

This would support the results of recent studies that found significant associations between these variables (Goff and Ackerman, 1992; Wolf and Johnson, 1995; De Raad and Schouwenburg, 1996; Chamorrow-Premuzic, 2003a, 2003b; Kappe and Flier, 2010).

Regarding emotional stability versus neuroticism as another significant indicator of academic performance and success, low emotional stability students have been shown to have lower academic achievement than stable students especially on examination because they worry about examinations, feel pressured during exams, and dislike being observed which negatively affects their academic achievement, Therefore, neuroticism is a good predictor of low academic achievement in most cases, especially in examinations. Therefore: 
Hypothesis 2: We expect that the emotional stability factor will be significantly and negatively related to academic achievement (examinations results) in both courses in our sample.

This would affirm previous findings (Furnham and Mitchelle 1991; Zeinder 1995; Zeinder and Matthews 2000; Chamorro-Premuzic and Furnham 2003a, 2003b) as well as reflect the modest and consistent positive association between neuroticism and examination anxiety (Zeidner and Matthews, 2000).

The third and last factor will be investigated in this study is extraversion versus introversion. Although extraversion includes qualities like dynamism, energy, and activity which are positive qualities for job performance and success, most extraverted students have lower academic achievement. This may be because they tend to be impulsive and have troubles concerning academic material because their more active social life and their recklessness (Entwistle and Entwistle 1970; Sanchez-Marin, Rejano-Infante, and Rodriguez-Troyano 2001). Furthermore, introverted students spend more time studying and reading than extraverted ones who spend more time with friends and at events (Rolfhus and Ackerman 1999). Therefore:

Hypothesis 3: We expect that extraversion will be negatively and significantly related to academic performance and achievement (examinations grades) in our sample.

This would be consistent with previous studies that reported negative relation between extraversion and knowledge examinations (e.g., Rolfhus and Ackerman, 1999; SanchezMarin, Rejano-Infante, Rodriguez-Troyano 2001).

Hypothesis 4: The Big Five factors on the whole can significantly predict academic performance and success as a general rule. 
This hypothesis is based on the previous predictions that refer to a significant association between academic performance and the three most important of the Big Five factors of personality (see $\mathrm{H} 1, \mathrm{H} 2$ and $\mathrm{H} 3$ ), as well as on diversity of recent empirical studies that found significant associations between established personality dimensions and several indicators of academic attainment (Goff and Ackerman, 1992; Wolfe and Johnson, 1995; De Raad and Schouwenburg, 1996; Chamorro-Premuzic and Furnham, 2003a, 2003b; O'Conner and Paunonen, 2007; Kappe and Flier, 2010). 


\section{Chapter Three}

\section{Methodology}

\subsection{Specific research objectives}

The particular objectives of this project are to:

1. Validate our questionnaire.

2. Optimize the metric qualities of the questionnaire by regrouping its items regarding to personality factors and traits.

3. Test the correlation between some personality factors of the Big Five factors Model (FFM) and academic performance.

4. Identify personality factors that are significantly correlated to academic performance and results in our sample.

5. Prove the validity of the personality factors as predictors of academic performance and achievement which can be generalized to predict the job performance and to enhance occupation matching regarding personality differences and tendencies of the individuals.

6. Propose a model for the general determinants of individual performance and behavior based on psychological characteristics (personality and attitudes).

\subsection{The sample}

The participants in this study are 209 undergraduate students (women and men) from the University of Quebec at Chicoutimi. All the participants are students in the administration sciences department. Most of the students are native French speakers and their initial ages range from 17 to 23 years. 


\subsection{Procedure}

\subsubsection{Methods of collecting the data}

In order to achieve the objectives of this study, our research proceeds by collecting the data through two levels of sources:

Firstly, the academic results of the students in each course were collected and appeared in the obtained profiles of the participants. The grades were collected from the archives of the University of Quebec at Chicoutimi.

Secondly, a personality questionnaire of 37 items was addressed to the participants (our sample), based on a number of important personality dimensions and traits such as extraversion, conscientiousness, emotional stability, self-esteem, locus of control, sense of personal efficacy, as well as work (learning) and life satisfaction. They completed the questionnaire at the beginning of their courses and took several oral and written examinations throughout their academic year. The questionnaire involved statements about typical behavior or reactions that were answered on a five point Likert scales, ranging from "strongly no or disagree" to "strongly yes or agree".

\section{$>$ Questionnaire}

The personality questionnaire is an instrument used to describe or evaluate the characteristics of the personality under investigation. It consists of a set of questions designed to reveal aspects of an individual's self-evaluation composition. It allows the respondent to rate his relative agreement with 37 statements related to attitudes and behaviors.

Our questionnaire aims to evaluate some important personality factors of the Five Factors Model (FFM) besides some other personality traits not included in Big Five model as well as measuring the participant's degree of satisfaction in life in general and in work or study in particular.

The questionnaire statements concern the participant's self-perception in a variety of situations. The task is to indicate the strength of his agreement or disagreement 
with each statement, using a scale in which 1 means disagreement, 5 means strong agreement, and 2, 3 and 4 represent intermediate judgment. In each statement of the following box the respondent chose a number from 1 to 5 from the following scale:

1. Strongly disagree.

2. Disagree.

3. Neither disagree nor agree.

4. Agree.

5. Strongly agree

There are no "right" or "wrong" answers; the respondent chooses the number that most closely reflects their perception in each statement.

This is the questionnaire we have used in this study:

Using the following scale, declare your degree of agreement or disagreement with every statement:

$\begin{array}{lllll}1 & 2 & 3 & 4 & 5\end{array}$

Strongly disagree - disagree - neither disagree nor agree - agree - strongly agree

\begin{tabular}{|c|l|}
\hline 1. I have control over whatever happens to me. & Locus of control \\
\hline 2. I talk a lot. & Extraversion \\
\hline 3. My life is agreeable. & Life satisfaction. \\
\hline 4. I return things to their places. & Conscientiousness \\
\hline 5. I know my strong points. & Self-esteem \\
\hline 6. I terminate what I start. & Sense of efficacy \\
\hline 7. I feel good when I am with a group. & Extraversion \\
\hline 8. I am satisfied with my life. & Life satisfaction \\
\hline
\end{tabular}




\begin{tabular}{|l|l|}
\hline $\begin{array}{l}\text { 9. I am a perfectionist. } \\
\text { 10. When I make plans, I am almost sure to realize } \\
\text { them. }\end{array}$ & Sense of efficacy \\
\hline 11. I get back on my feet quickly. & Emotional stability \\
\hline 12. I talk to several people at a party. & Extraversion. \\
\hline 13. I like myself as I am. & Self-esteem \\
\hline 14. I intiate conversations. & Extraversion \\
\hline $\begin{array}{l}\text { 15. I am demanding in my work. } \\
\text { 16. I have a lot of friends. }\end{array}$ & Conscientiousness \\
\hline 17. Up to now, I have achieved the important things & Life satisfaction \\
\hline that I wanted to do in my life & \\
\hline 18. I like to feel responsible for my decisions. & Self-esteem \\
\hline 19. I like order and regularity. & Conscientiousness \\
\hline 20. I put a good mood around me. & Extraversion \\
\hline 21. I can change many important things in my life. & Locus of control \\
\hline 22. Most of time, I am relaxed. & Emotional stability \\
\hline 23. I have established timetables. & Conscientiousness \\
\hline 24. If I could relive my life one more time, I would & Life satisfaction. \\
\hline 26. I am an optimistic person. & Conscientiousness \\
\hline
\end{tabular}




\begin{tabular}{|l|l|}
\hline 27. My room is in order. & Conscientiousness \\
\hline 28. It doesn't annoy me to be the center of attention. & Extraversion \\
\hline 29. I am punctual. & Conscientiousness \\
\hline 30. I am silent with people that I don't know. & Extraversion \\
\hline 31. I feel that I am a valuable person. & Self-esteem \\
\hline 32. I finish what I undertake. & Sense of efficacy \\
\hline 33. I stay away from people. & Extraversion \\
\hline 34. As a student, I am satisfied. & Job satisfaction \\
\hline 35. I am always prepared. & Conscientiousness \\
\hline 36. I feel that I don't have great things to be proud of. & Self-esteem \\
\hline 37. I adapt to all situations. & Locus of control \\
\hline
\end{tabular}

\section{Table 1: Questionnaire}

Regarding the personality factors and traits in our questionnaire, the items of the questionnaire aimed to evaluate some important personality factors and traits. Some of these factors are already included in Big Five Model (FFM): extraversion, conscientiousness, neuroticism or emotional stability, as well as other personality traits not included in the Big Five Model such as; self-esteem, locus of control, sense of efficiency, emotional intelligence and satisfaction. The results of the questionnaire provide a scale showing to what extent the participant showed a preference for each of the previous factors and traits.

Personality factors included in (FFM)

\begin{tabular}{|c|c|c|}
\hline $\begin{array}{c}\text { High scored in the } \\
\text { factor }\end{array}$ & Personality factor & Low scored in the factor \\
\hline
\end{tabular}




\begin{tabular}{|c|c|c|}
\hline $\begin{array}{l}\text { The person tends to be } \\
\text { reliable, well-organized, } \\
\text { mindful of details, } \\
\text { careful and responsible. }\end{array}$ & $\begin{array}{l}\text { 1. Conscientiousness } \\
\text { Refers to qualities such as order, } \\
\text { self-discipline, dutifulness, } \\
\text { striving for goals, aiming for } \\
\text { achievement, thoughtfulness, } \\
\text { competence, deliberation and } \\
\text { sense of responsibility. }\end{array}$ & $\begin{array}{l}\text { The person tends to be } \\
\text { disorganized, } \\
\text { undependable and } \\
\text { negligent. }\end{array}$ \\
\hline $\begin{array}{l}\text { The person tends to be } \\
\text { nervous, high-strung, } \\
\text { easily-stressed, insecure, } \\
\text { tense, worryied and } \\
\text { moody }\end{array}$ & $\begin{array}{l}\text { 2. Neuroticism } \\
\text { Refers to emotional instability, } \\
\text { anxiety, moodiness, irritability, } \\
\text { sadness, ease of anger, hostility, } \\
\text { high susceptibility to depression, } \\
\text { impulsiveness and vulnerability. }\end{array}$ & $\begin{array}{l}\text { The person tends to be } \\
\text { calm, patient, relaxed, } \\
\text { secure and not easily } \\
\text { angered. }\end{array}$ \\
\hline $\begin{array}{l}\text { The person tends to be } \\
\text { sociable, friendly, fun- } \\
\text { loving, talkative, } \\
\text { energetic and assertive }\end{array}$ & $\begin{array}{l}\text { 3. Extraversion } \\
\text { Refers to characteristics suchas } \\
\text { sociability, talkativeness, } \\
\text { warmth, unreservedness, positive } \\
\text { emotions, high capacity for } \\
\text { communication with people and } \\
\text { emotional expressiveness. }\end{array}$ & $\begin{array}{l}\text { Introverted, reserved, } \\
\text { inhibited and quiet. }\end{array}$ \\
\hline
\end{tabular}

Table 2: Questionnaire personality factors included in FFM

\section{Personality traits not included in (FFM) and Satisfaction}

\section{Self esteem}

This is a person's self-judgment or evaluation regarding values and standards.

Self-esteem does not carry any requirement of accuracy whatsoever. Thus, high self-esteem may refer to an accurate, justified, balanced appreciation of one's worth as a person and one's successes and competencies, but it can also refer to an inflated, arrogant, grandiose, 
unwarranted sense of superiority over others. By the same token, low self-esteem can be either an accurate, well-founded understanding of one's shortcomings as a person or a distorted, even pathological sense of insecurity and inferiority. Thus, self-esteem is a perception rather than reality. It is a person's belief about himself. High self-esteem refers to a highly favourable global evaluation of the self. People with high self-esteem have confidence in their intelligence and abilities to think, to deal with and to conquer the challenges of life. They have a positive image of self in the whole (www.ukessays.com). Low self-esteem refers to a negative perception about one's worth and abilities. It is often characterized by a lack of confidence, negative thinking and difficulty making decisions and communicating needs effectively (www.utsc.utoronto.ca).

\section{Locus of control}

This is a psychological concept which was first proposed by Julian Rotter in 1954. It refers to the fact that individuals differ in their appreciations and beliefs about the causes or the determinants of their outcomes in a particular activity, a particular context, whatever affects their life. In other words, it refers to an individual's perception of the underlying main causes of events in their life.

There are two orientations of locus of control:

\section{A. External Locus of Control:}

Individual believes that his/her behaviour is guided by fate, luck, or other external circumstances.

\section{B. Internal Locus of Control}

Individual believes that his/her behaviour is guided by his/her personal decisions and efforts (www.wilderdom.com)

\section{The sense of personal efficacy}

This is a person's convictions that they are able to organize and execute the necessary requirements and actions to successfully accomplish a particular task.

In other words, self-efficacy is a person's belief in his or her ability to succeed in a particular situation. Bandura (1994) declared that these beliefs affect how people think, behave, and feel. 


\section{Emotional intelligence (EI)}

Emotional intelligence is the ability to recognize the own emotions, understand what they are saying, and realize how they affect other people.

Emotional intelligence also involves a person's perception of others; when the person understands how other people feel, this allows him/her to manage relationships more effectively.

People with high emotional intelligence are usually successful in most things they do because they are the ones that others want on their team. When people with high EI send an email, it gets answered. When they need help, they get it because they make others feel good. They go through life much more easily than people who are easily angered or upset.

\section{Satisfaction:}

\section{Life satisfaction}

Reveals the person's perception of how his life is going and how he feels about where it is going in the future. It is a measure of well being as well as a cognitive, global judgment. It reflects the level of satisfaction or dissatisfaction of a person about his life as a whole.

\section{Job satisfaction}

Job satisfaction is a compilation of feelings and beliefs that a person has about his/her existing job. People's level of job satisfaction can range from extreme satisfaction to extreme dissatisfaction. Positive and favorable feelings and behavior toward the job reflect job satisfaction. Negative and discouraged feelings toward the job reflect job dissatisfaction.

\section{Table 3: Questionnaire personality factors not included in FFM}

\subsubsection{The variables of the research}

\section{Independent variables}

1) Personality traits, as they are assessed by a self-report questionnaire. Each of the following personality traits represents a variable of the independent variables of the present study.

2) The courses (marketing and accounting). 


\begin{tabular}{|c|c|c|}
\hline $\begin{array}{l}\text { Personality dimensions } \\
\text { included in (FFM) }\end{array}$ & Personality traits & satisfaction \\
\hline $\begin{array}{l}\text { 1. Conscientiousness } \\
\text { 2. Neuroticism } \\
\text { 3. Extraversion }\end{array}$ & $\begin{array}{l}\text { 1. Self esteem. } \\
\text { 2. Locus of control. } \\
\text { 3. Sense of personal efficacy. } \\
\text { 4. Emotional intelligence (EI). }\end{array}$ & 1. Life satisfaction \\
\hline
\end{tabular}

\section{Table 4: Independent Variables}

Each item or statement in the questionnaire evaluates a particular aspect of the independent variables, for example, the statement "I talk to several people at a party." reflects extraversion. The statement "up to now, I have achieved the important things that I wanted to do in my life" refers to the degree of the satisfaction of life, and so on.

Accordingly, each personality variable was evaluated by one or more items of the questionnaire. By regrouping the items regarding the personality factors and traits (the independent variable of the research), we see that;

- The items concerning Conscientiousness are:

Q4 : I return things to their places.

Q9 : I am a perfectionist.

Q15: I am demanding in my work.

Q19: I like order and regularity.

Q23: I have established timetables.

Q25: I do chores as soon as possible

Q27: My room is in order

Q29: I am punctual.

Q35: I am always prepared.

- The items concerning Emotional stability are:

Q11: I get back on my feet quickly.. 
Q22: Most of time, I am relaxed.

- The items concerning Extraversion are:

Q2: I talk a lot.

Q7: I feel good when I am with a group.

Q12: I talk to several people at a party.

Q14: I initiate conversations.

Q16: I have a lot of friends.

Q20: I put a good mood around me.

Q26: I am an optimistic person.

Q28: It doesn't annoy me to be the center of attention.

Q30: I am silent with people that I don't know (reversed score).

Q33: I stay always away from people (reversed score).

- The items concerning $\underline{\text { Self-esteem are: }}$

Q5: I know my strong points.

Q13: I like myself as I am.

Q18: I like to feel responsible for my decisions.

Q31: I feel that I am a valuable person.

Q36: I feel that I don't have great things to be a proud of (reversed score).

- The items concerning Locus of control are:

Q1: I have control over whatever happens to me.

Q21: I can change many important things in my life.

- The items concerning Sense of efficacy:

Q6: I terminate what I start

Q10: When I make plans, I am almost sure that I will realize them.

Q32: I finish what I undertake.

- The items concerning life satisfaction are: 
Q3: My life is agreeable.

Q8: I am satisfied with my life.

Q17: Up to now, I have achieved the important things I wanted to do in my life.

Q24: If I could relive my life one more time, I would change almost nothing.

- The items concerning job satisfaction are:

Q34: As a student, I am satisfied.

\section{Dependant variables:}

The dependent variable is the academic performance measured by the examination grades of the participants of each of the two selected courses (marketing and accounting).

\subsection{Measures}

Our measure of academic performance and achievement of the participants is based on the overall exams marks in each course (marketing and accounting).

\subsection{Tools of analysis}

SPSS (Statistical Program for Social Sciences) was used for analyzing the data. Descriptive statics, correlations, factorial analysis, and regression analysis were carried out in order to:

1. Profile the sample under study.

2. Measure the validity of the questionnaire.

3. Find clusters, if they exist, in independent variables.

4. Identify the differences between the variables explaining academic success in marketing and in accounting.

5. Analyse the academic results of the sample in both courses in general and each course in particular.

6. Examine the correlation between the variables of personality and academic results and success. 
4. Identify the variables which have positive or negative effect on academic success.

5. Identify which variables are most significantly correlated to academic results. 


\section{Chapter Four}

\section{Analysis}

\subsection{Sample analysis}

Our sample consists of 209 students, but there is some of students data are missed, since some of them have not indicated all of their personal information, this missing data is represented by (Missing System) in the analysis tables. A descriptive analysis of the sample follows.

\subsubsection{Gender of participants}

The sample consists of 109 women, 97 men and 3 participants who have not indicated their sex (Missing data). Women represent $52.2 \%$ of the sample and men represent $46.4 \%$.

\section{Gender of participant}

\begin{tabular}{|ll|r|r|r|r|}
\hline & Frequency & Percent & Valid Percent & $\begin{array}{c}\text { Cumulative } \\
\text { Percent }\end{array}$ \\
\hline Valid & Female & 109 & 52,2 & 52,9 & 52,9 \\
& Male & 97 & 46,4 & 47,1 & 100,0 \\
& Total & 206 & 98,6 & 100,0 & \\
Missing & System & 3 & 1,4 & & \\
Total & & 209 & 100,0 & & \\
\hline
\end{tabular}

Table 5: Gender of participant 


\subsubsection{Title of course}

Three participants neglect to identify the title of their course. Of the other 206 participants, there are 94 students in the Marketing course (45.6\%) and 112 students in the Accounting course (54.4\%), as shown in the following table.

Title of course

\begin{tabular}{|ll|r|r|r|r|}
\hline & Frequency & Percent & Valid Percent & $\begin{array}{c}\text { Cumulative } \\
\text { Percent }\end{array}$ \\
\hline Valid & Marketing & 94 & 45,0 & 45,6 & 45,6 \\
& Accounting & 112 & 53,6 & 54,4 & 100,0 \\
& Total & 206 & 98,6 & 100,0 & \\
Missing & System & 3 & 1,4 & & \\
Total & & 209 & 100,0 & & \\
\hline
\end{tabular}

Table 6: Title of course

\subsubsection{Course results (Success)}

Results were obtained for 189 of the 209 participants $(90.4 \%)$. For the other 20 participants, results were not available $(9.6 \%)$.

Case Processing Summary

\begin{tabular}{|c|c|c|c|c|c|c|}
\hline & \multicolumn{6}{|c|}{ Cases } \\
\hline & \multicolumn{2}{|c|}{ Valid } & \multicolumn{2}{|c|}{ Missing } & \multicolumn{2}{|c|}{ Total } \\
\hline & $\mathrm{N}$ & Percent & $N$ & Percent & $N$ & Percent \\
\hline $\begin{array}{l}\text { Exams results * Title of } \\
\text { course }\end{array}$ & 189 & $90,4 \%$ & 20 & $9,6 \%$ & 209 & $100,0 \%$ \\
\hline
\end{tabular}

Table 7: Results summary

According to the success standards of undergraduate studies of University of Quebec at Chicoutimi (UQAC): 
I. The total number of students who succeeded in both courses is $107(56.6 \%)$.

II. The number of students who succeeded in the Marketing course is $65(71.4 \%)$.

III. The number of students who succeeded in the Accounting course is 42 $(42.9 \%)$.

The exam results of the participants in each course are illustrated in the following table:

\section{Exams results * Title of course Cross tabulation}

\begin{tabular}{|c|c|c|c|c|c|}
\hline & & & Title o & course & \\
\hline & & & Marketing & Accounting & Total \\
\hline Exams results & failure & $\begin{array}{l}\text { Count } \\
\% \text { within Course results } \\
\% \text { within Title of course } \\
\% \text { of Total }\end{array}$ & $\begin{array}{r}26 \\
31,7 \% \\
28,6 \% \\
13,8 \%\end{array}$ & $\begin{array}{r}56 \\
68,3 \% \\
57,1 \% \\
29,6 \%\end{array}$ & $\begin{array}{r}82 \\
100,0 \% \\
43,4 \% \\
43,4 \%\end{array}$ \\
\hline & Success & $\begin{array}{l}\text { Count } \\
\% \text { within Course results } \\
\text { (within success students) } \\
\% \text { within Title of course } \\
\% \text { of Total (within all } \\
\text { students success \& failure) }\end{array}$ & $\begin{array}{r}65 \\
60,7 \% \\
71,4 \% \\
34,4 \%\end{array}$ & $\begin{array}{r}42 \\
39,3 \% \\
42,9 \% \\
22,2 \%\end{array}$ & $\begin{array}{r}107 \\
100,0 \% \\
56,6 \% \\
56,6 \%\end{array}$ \\
\hline Total & & $\begin{array}{l}\text { Count } \\
\% \text { within Course results } \\
\% \text { within Title of course } \\
\% \text { of Total }\end{array}$ & $\begin{array}{r}91 \\
48,1 \% \\
100,0 \% \\
48,1 \%\end{array}$ & $\begin{array}{r}98 \\
51,9 \% \\
100,0 \% \\
51,9 \%\end{array}$ & $\begin{array}{r}189 \\
100,0 \% \\
100,0 \% \\
100,0 \%\end{array}$ \\
\hline
\end{tabular}

Table 8: Exam results in each course

As indicated by these results, the number of students who succeeded in the Marketing course (65) is greater than in the Accounting course (42). $71.4 \%$ of Marketing students passed their exams, while just $42.9 \%$ of the Accounting students did so. Then, Merketing course has a success percentage higher than that of Accounting course. The following diagram shows the success and failure percentage of each course. 


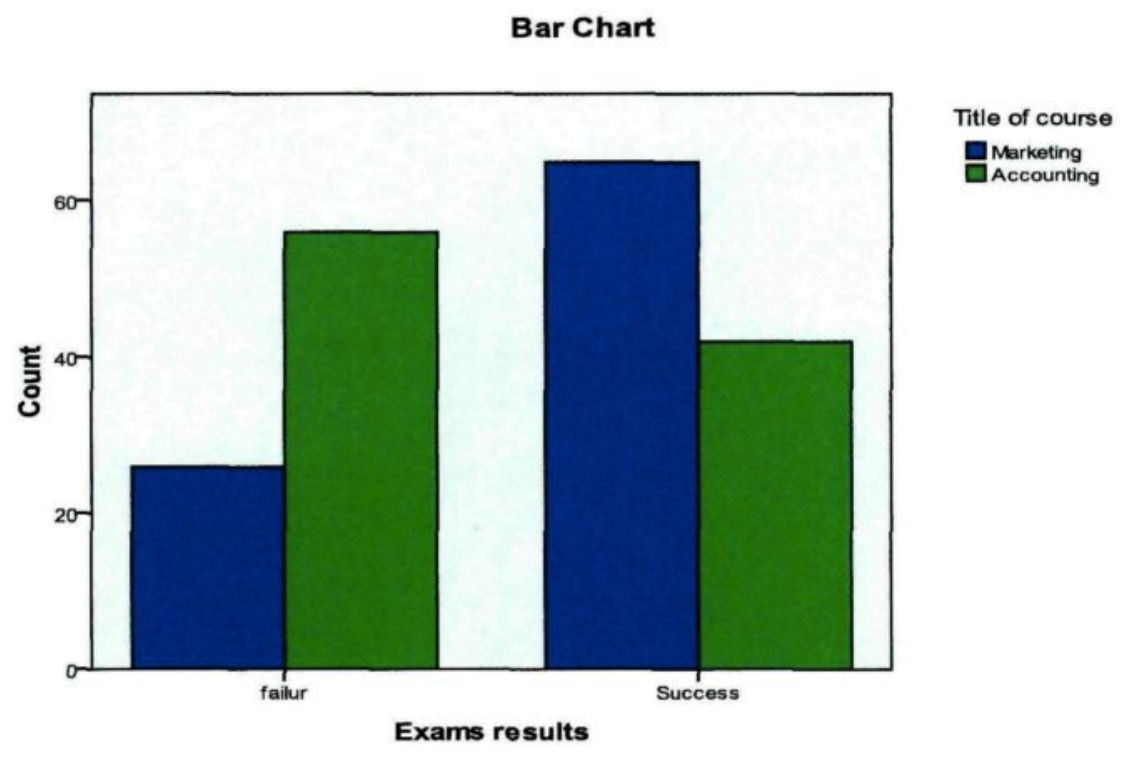

Figure 3: Exam results in each course

\subsubsection{Exam grades:}

Standard grade values of the University of Quebec at Chicoutimi:

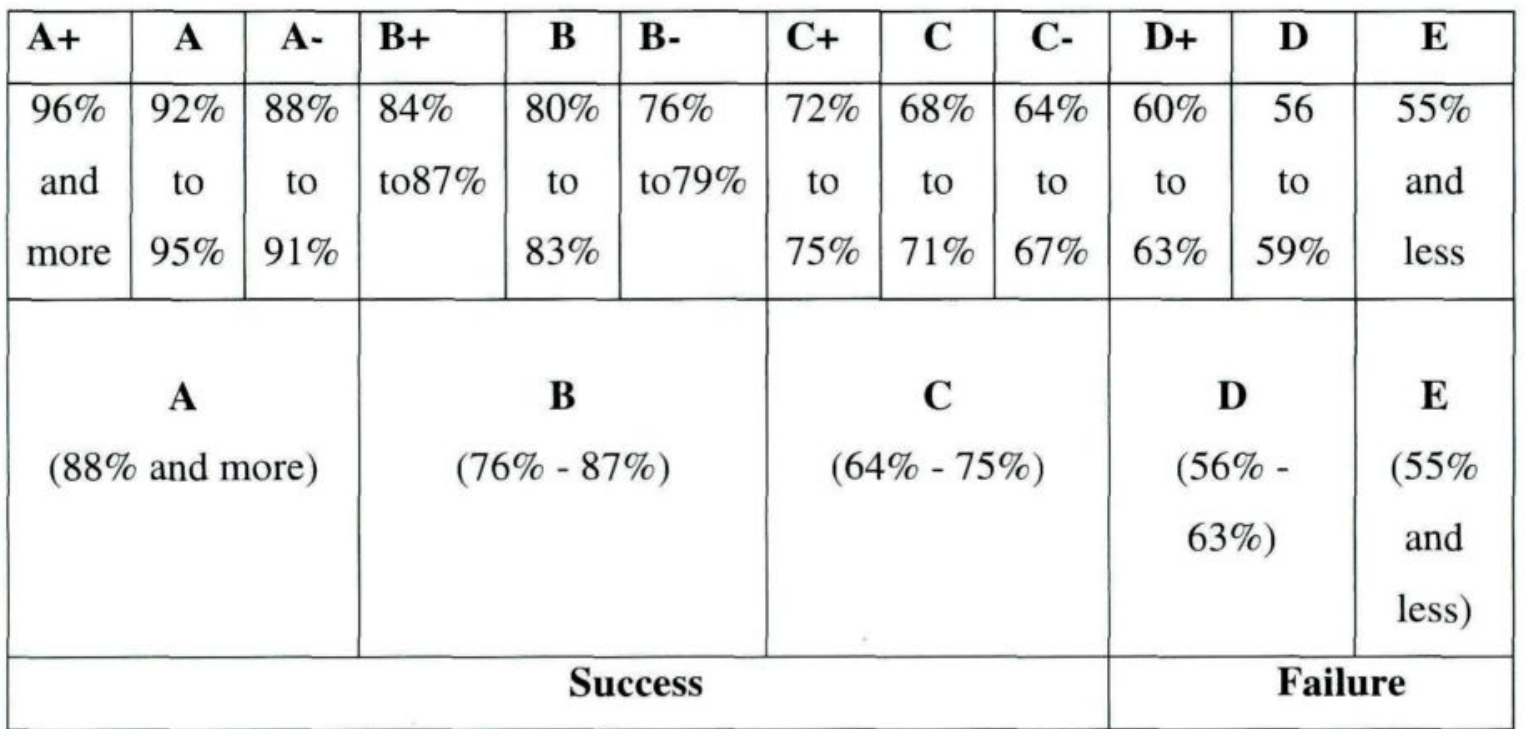

\section{Table 9: Standard grades values of UQAC}

I. 19 students of Marketing had grade A (20.9\% of Markiting students) compared to 4 students $(4.1 \%)$ in the Accounting course. 
II. 28 students of Marketing had grade B (30.8\% of Marketing students) compared to 16 students (16.3\%) in the Accounting course..

IV. 18 students of Marketing had C (19.8\% of Marketing students) compared to 22 students (22.4\%) in the Accounting course.

V. 11 students of Marketing had D (12.1\% of Marketing students) compared to 15 students (15.3\%) in the Accounting course.

VI. 15 students of Marketing had E (16.5\% of Marketing students) compared to 41 students (41.8\%) in the Accounting course.

Exam grades * Title of course Cross tabulation

\begin{tabular}{|c|c|c|c|c|c|}
\hline & & & Title $\mathrm{c}$ & course & \\
\hline & & & Marketing & Accounting & Total \\
\hline Course Grades & A & Count & 19 & 4 & 23 \\
\hline & & $\%$ within Course Grades & $82,6 \%$ & $17,4 \%$ & $100,0 \%$ \\
\hline & & $\%$ within Title of course & $20,9 \%$ & $4,1 \%$ & $12,2 \%$ \\
\hline & B & Count & 28 & 16 & 44 \\
\hline & & $\%$ within Course Grades & $63,6 \%$ & $36,4 \%$ & $100,0 \%$ \\
\hline & & $\%$ within Title of course & $30,8 \%$ & $16,3 \%$ & $23,3 \%$ \\
\hline & $\mathrm{C}$ & Count & 18 & 22 & 40 \\
\hline & & $\%$ within Course Grades & $45,0 \%$ & $55,0 \%$ & $100,0 \%$ \\
\hline & & $\%$ within Title of course & $19,8 \%$ & $22,4 \%$ & $21,2 \%$ \\
\hline & D & Count & 11 & 15 & 26 \\
\hline & & $\%$ within Course Grades & $42,3 \%$ & $57,7 \%$ & $100,0 \%$ \\
\hline & & $\%$ within Title of course & $12,1 \%$ & $15,3 \%$ & $13,8 \%$ \\
\hline & $\mathrm{E}$ & Count & 15 & 41 & 56 \\
\hline & & $\%$ within Course Grades & $26,8 \%$ & $73,2 \%$ & $100,0 \%$ \\
\hline & & $\%$ within Title of course & $16,5 \%$ & $41,8 \%$ & $29,6 \%$ \\
\hline Total & & Count & 91 & 98 & 189 \\
\hline & & $\%$ within Course Grades & $48,1 \%$ & $51,9 \%$ & $100,0 \%$ \\
\hline & & $\%$ within Title of course & $100,0 \%$ & $100,0 \%$ & $100,0 \%$ \\
\hline
\end{tabular}

Table 10: Exam grades in each course 
Based on these results, it is clear that the students in the Marketing course had relatively higher grades compared with accounting students. The following diagram illustrates the differences between the students achievement (grades) in each course.

\section{Bar Chart}

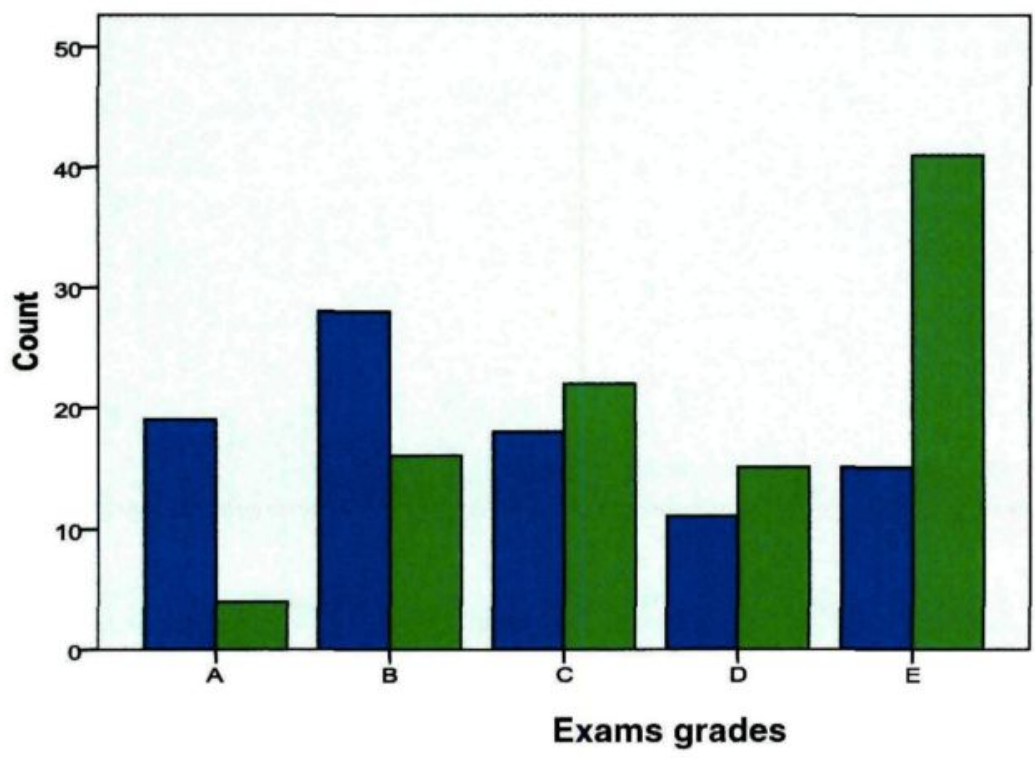

Title of course

Marketing

$\square$ Accounting

Figure 4: Exam grades in each course

\subsection{Correlation analysis}

The objective of this analysis is to investigate the relationship between the variables of personality and grades in the sample. We tested the research hypotheses and measured the degree of possible correlations between the variables, if these were significant. A correlation test was conducted to examine these relationships.

\section{$>$ Correlation Test}

Correlation test is used to find the degree of relationship or correlation between two or more variables. In the current research the correlation test was used to measure the strength of association between the variables of personality and the grades of the participants. The value for a Pearson's (the unit measure of 
correlation) can fall between $-1 \leq r \leq+1$ ( 0.00 indicates no correlation, 1.00 indicates a perfect positive correlation and -1 a perfect negative correlation). The fixed degree of confidence in the results (the confidence interval) is $0.05(95 \%)$. This shows the degree of association, or how significantly the concerned variables are related to each other. (Sig. value or p-value indicates the significance of the correlation between the two variables; significant correlation when p-value is less than 0.05 " $p<0.05$ or $p<.01$ ").

Note: In the case of a small sample size (such as ours), moderate correlations may misleadingly not reach significance, but with a large sample size small correlations may misleadingly turn out to be significant. Some researchers think that significance should be reported but perhaps should receive less focus (www.statistics-help-for-students.com)

\subsubsection{The correlation between conscientiousness and grades}

In this part of the analysis we will evaluate the relationship between the questionnaire items concerning conscientiousness (Q4, Q9, Q15, Q19, Q23, Q25, Q27, Q29, and Q35) and the exam grades of the participants to discover if there is a correlation between conscientiousness and grades. Each question in this category aims to evaluate a particular subfacet or characteristic of conscientiousness as follows:

Q4: I return things to their places.

Q9: I am a perfectionist.

Q15: I am demanding in my work.

Q19: I like order and regularity.

Q23: I have established timetables.

Q25: I do chores as soon as possible

Q27: My room is in order

Q29: I am punctual.

Q35: I am always prepared. 
- H1 (research hypothesis): There is a relationship between conscientiousness and high exam grades in both courses.

- H0 (null hypothesis): There is no relationship between conscientiousness and high exam grades in both courses.

\section{Correlations}

\begin{tabular}{|ll|r|r|r|r|r|r|r|r|r|r|}
\hline & & Grades & $\begin{array}{c}\text { Cons. } \\
\text { Q4 }\end{array}$ & $\begin{array}{c}\text { Cons. } \\
\text { Q9 }\end{array}$ & $\begin{array}{c}\text { Cons. } \\
\text { Q15 }\end{array}$ & $\begin{array}{c}\text { Cons. } \\
\text { Q19 }\end{array}$ & $\begin{array}{c}\text { Cons. } \\
\text { Q23 }\end{array}$ & $\begin{array}{c}\text { Cons. } \\
\text { Q25 }\end{array}$ & $\begin{array}{c}\text { Cons. } \\
\text { Q27 }\end{array}$ & $\begin{array}{c}\text { Cons. } \\
\text { Q29 }\end{array}$ & $\begin{array}{c}\text { Cons. } \\
\text { Q35 }\end{array}$ \\
\hline $\begin{array}{llll}\text { Spear Grades } \\
\text { man's }\end{array}$ & $\begin{array}{l}\text { Correlation } \\
\text { Coefficient }\end{array}$ & 1,000 &, 057 &, 050 &, $389^{* *}$ &, 109 &, 136 &, $171^{*}$ &,- 022 &, 058 &, $309^{* *}$ \\
& $\begin{array}{l}\text { Sig. (2- } \\
\text { tailed) }\end{array}$ & &, 432 &, 493 &, 000 &, 134 &, 062 &, 018 &, 768 &, 428 &, 000 \\
& $\mathrm{~N}$ & 189 & 189 & 189 & 189 & 189 & 189 & 189 & 189 & 189 & 189 \\
\hline
\end{tabular}

**. Correlation is significant at the 0.01 level (2-tailed).

*. Correlation is significant at the 0.05 level (2-tailed).

Table 11: Correlation between conscientiousness and grades

According to the previous results, conscientiousness is positively correlated with grades, evidently at Q 15, Q 25 and Q 35 which were the most significantly and positively correlated with grades $r=.389, p<.001(p=.000)$ for Q15, $r=.171, p<.05(p=.018)$ for Q25, and $r=.309, p<.001(p=.000)$ for Q35. These significant positive correlations can be justified by the characteristics or the subfacets of the conscientiousness factor that these questions have aimed to evaluate. For example; Q15 (I am demanding in my work) has aimed to evaluate the punctuality and dutifulness (the tendency of perfection/solicitous/attentiveness/caring). Since these characteristics of conscientiousness are essential for academic success and achievement, it was normal that high scoring in this area leads to higher academic perfomance and achievement (higher exam grades). Similarly for Q25 (I do chores as soon as possible) which evaluates orderliness and organizing, and Q35 (I am always prepared) which evaluates orderliness and planning. All these subfacets are most effective and influential on 
academic performance; they touch it most directly and are the most related to it. They are vital supportive features for academic success and high achievement; high scoring in these subfacets leads necessarily to higher academic performance and achievement.

The significant correlation between Q15, Q25, and Q35 and exam grades have confirmed that there is positive and significant correlation between conscientiousness and grades. This means scoring in conscientiousness does significantly relate to grades in the same way, which means high scoring in conscientiousness is positively correlated with higher grades in the population.

Therefore, we can conclude that there is a significant positive relationship between conscientiousness and exam grades. Consequently, we reject $\mathrm{HO}$ and accept $\mathrm{H} 1$ and conclude that the factor of conscientiousness is significantly and positively associated with exam grades in the population.

\subsubsection{The correlation between emotional stability and grades:}

For the second part of correlation analysis, we examine the association between emotional stability and grades, as measured by the items Q11 and Q22. Each of these questions evaluates a particular characteristic or indicator of this factor as follows:

Q11: I get back on my feet quickly..

Q22: Most of time, I am relaxed.

We examine the research hypotheses concerning emotional stability which are:

- H1 (research hypothesis): There is a significant positive relationship between emotional stability and grades.

- H0 (null hypothesis): There is no relationship between emotional stability and grades. 


\section{Correlations}

\begin{tabular}{|c|c|c|c|c|}
\hline & & Grades & $\begin{array}{c}\text { Emotional Stab. } \\
\text { Q11 }\end{array}$ & $\begin{array}{c}\text { Emotional Stab. } \\
\text { Q22 }\end{array}$ \\
\hline $\begin{array}{l}\text { Spearman's Grades } \\
\text { rho }\end{array}$ & $\begin{array}{l}\text { Correlation } \\
\text { Coefficient } \\
\text { Sig. (2-tailed) } \\
\mathrm{N}\end{array}$ & $\begin{array}{r}1,000 \\
189\end{array}$ & $\begin{array}{r}-, 054 \\
, 460 \\
189\end{array}$ & $\begin{array}{r}-, 141 \\
, 054 \\
189\end{array}$ \\
\hline
\end{tabular}

\section{Table 12: Correlation between emotional stability and grades}

The results of the correlation test of emotional stability items (Q11 and Q22) and grades indicate that there is a very small negative relationship between Q11 and the grades $(r=$ -.054), but the Sig. value of this correlation indicates that this negative correlation is not significant $(p=.46)$. This means that the two variables are not significantly correlated, which means that changes in Q11 scores are not correlated with changes in exam grades.

The correlation results of the second emotional stability question (Q22) indicate that there is a small negative correlation between this question and the grades $(r=-.141)$, and the Sig. value $p=.054$ indicates that this correlation is not significant $(p>.05)$.

Based on the correlation results of the two questions of emotional stability and grades in both courses, emotional stability appears bizarrely to be insignificantly correlated with grades (there was no significant or reliable correlation between any item of emotional stability and grades). Although there were weak negative correlations between the two questions of emotional stability and grades $(r=-.054$ for Q11 and $r=-.141$ for Q22), these relationships are not reliable or significant $(\mathrm{p}>.05$ for both of questions; $p=.46$ for $\mathrm{Q} 11$ and $p=.054$ for $\mathrm{Q} 22$ ). This means that these correlations are not significant and may have happened by chance; that there was not a real relationship between the variables. Although the correlation between Q22 and exam grades was marginally significant (the Sig. value was close to the present value of alpha or the confidence 
interval of 0.05) $P=.054$, but we can't declare it as significant or a reliable correlation. Consequently, we reject $\mathrm{H} 1$ and accept $\mathrm{H} 0$ which concludes that there is no significant correlation between emotional stability and exam grades in the sample.

\subsubsection{The correlation between extraversion and grades in both courses}

In this part of analysis we investigate the questionnaire items concerning extraversion (Q2, Q7, Q12, Q14, Q16, Q20, Q26, Q28, Q30, and Q33) to determine whether there is a correlation between extraversion and grades and to assess the value of this correlation. Each of these questions evaluates a particular characteristic or subfacet of this factor as follows:

Q2: I talk a lot.

Q7: I feel good when I am with a group.

Q12: I talk to several people at a party.

Q14: I initiate conversations.

Q16: I have a lot of friends.

Q20: I put a good mood around me.

Q26: I am an optimistic person.

Q28: It doesn't annoy me to be the center of attention.

Q30: I am silent with people that I don't know (reversed score).

Q33: I stay always away from people (reversed score).

This part of the analysis examines the following hypotheses:

- Hypothesis 1 (research hypothesis): There is a significant negative relationship between extraversion and exam grades in both courses.

- Hypothesis 0 (null hypothesis): There is no relationship between extraversion and exam grades in both courses. 


\section{Correlations}

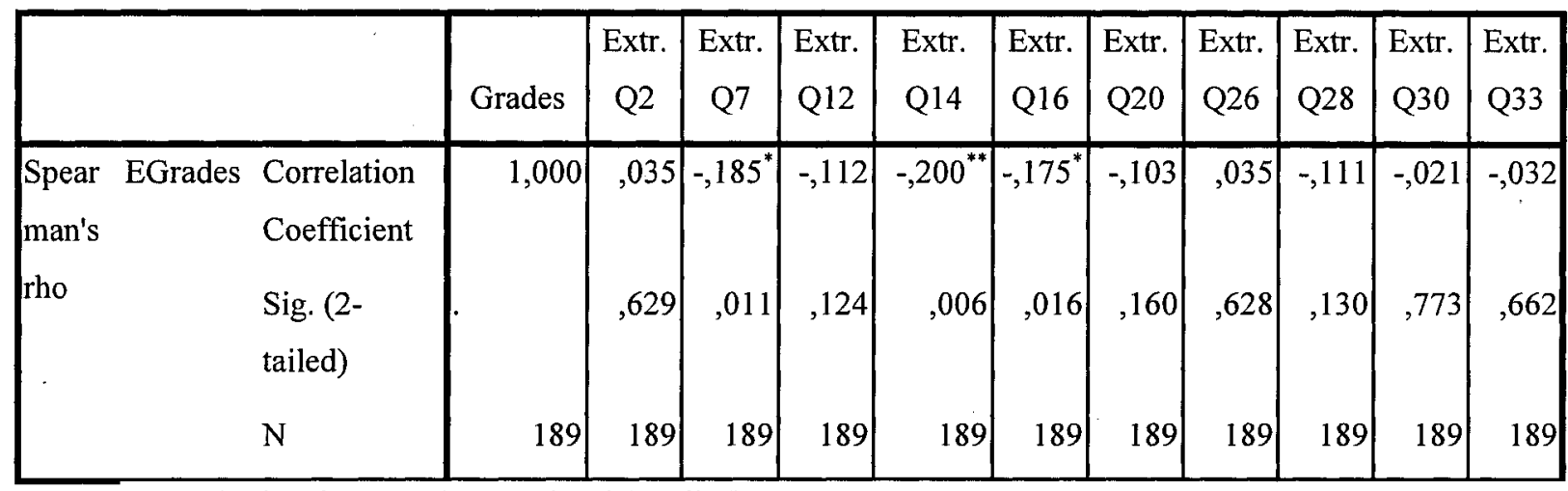

*. Correlation is significant at the 0.05 level (2-tailed).

**. Correlation is significant at the 0.01 level (2-tailed).

Table 13: Correlations between extraversion and grades

The previous correlation results between extraversion items and grades shows that there are negative and significant correlations between extraversion and the exam grades in both of courses $(r=-.185, p<.05$ " $P=.011$ ") for Q7, $(r=-.2, p<.01$ " $p=.006$ ") forQ14 and $(r=-.175, p<.05$ " $p=.016 ")$ for Q16. This means that higher scoring in extraversion related significantly to lower exam grades in our sample. Which means students with high extraversion scores obtained lower exam grades. Consequently, we reject $\mathrm{H} 0$ and accept $\mathrm{H} 1$ and conclude that extraversion was negatively and significantly correlated with exam grades in both of courses. Correlations between Q2, Q26, Q30 and $\mathrm{Q} 33$ are not significative $(\mathrm{p}>.05)$.

In conclusion, the correlation test of the super FFM factors (conscientiousness, emotional stability, and extraversion) and grades showed that conscientiousness is positively and significantly correlated with grades, and that extraversion is negatively and significantly correlated with exam grades, whereas there was no significant correlation between emotional stability and grades. Consequently, conscientiousness and extraversion are significantly linked with grades in our sample, while emotional stability cannot be significantly associated with grades. The correlation analysis has confirmed $\mathrm{H} 1$ and $\mathrm{H} 3$, whereas $\mathrm{H} 2$ was not confirmed. 


\subsection{Regression Analysis}

Because conscientiousness and extraversion were found to be most constantly and significantly correlated with grades, it was interesting to regress the grades of our students onto conscientiousness and extraversion factors to test the predictability of exam grades by these two super factors of FFM. An ordinal regression test was conducted to evaluate the contribution of conscientiousness and extraversion in the prediction of academic grades.

\section{Ordinal Regression Test}

This is typically used to predict an ordinal dependant variable (DV) with an independent variable (IV) or multiple IVs. The IV is the predictor and the DV is the criterion (the variable that we want to predict). This test is related to the correlation test and is used for the same objective (to examine the relationship between two or more variables). In our regression analysis, conscientiousness and extraversion scores served as independent variables and the exam grades were the dependant variables.

\subsubsection{Conscientiousness/ exam grades regression analysis}

The hypotheses that will be tested in this analysis are:

- H1 (Research hypothesis): Conscientiousness is a positive and significant predictor of exam grades.

- H0 (Null hypothesis): There is no relationship between conscientiousness and exam grades.

The detailed results of conscientiousness/exam grades regression test are explained by following:

\section{Model Fitting Information table}

Before looking at the effects of each explanatory variable in the model, we need to determine whether the model improves our ability to predict the outcome. We do this by comparing a model without any explanatory variables (the baseline or 'Intercept Only' 
model) against the model with all the explanatory variables (the 'Final' model). We compare the final model with the baseline to see whether it has significantly improved the fit to the data. The Model fitting Information table gives the $-2 \log$-likelihood (-2LL) values for the baseline and the final model, and a chi-square has been performed to test the difference between the -2LL for the two models.

Model Fitting Information

\begin{tabular}{|l|r|r|r|r|}
\hline Model & \multicolumn{1}{|c|}{$\begin{array}{c}-2 \text { Log } \\
\text { Likelihood }\end{array}$} & Chi-Square & df & Sig. \\
\hline Intercept Only & 583,798 & & & \\
Final & 537,449 & 46,350 & & 9 \\
\hline
\end{tabular}

Link function: Logit.

Table 14: Conscientiousness Model Fitting Information table

\section{Goodness-of-Fit table}

The statistically significant chi-square statistic $(p<.001)$ indicates that the final model is a significant improvement over the baseline intercept-only model. This tells us that the model gives predictions that are better than chance, based on the marginal probabilities for the outcome categories.

\section{Goodness-of-Fit}

\begin{tabular}{|l|r|r|r|}
\hline & Chi-Square & \multicolumn{1}{c|}{ df } & \multicolumn{1}{c|}{ Sig. } \\
\hline Pearson & 711,273 & 723 &, 615 \\
Deviance & 533,054 & 723 & 1,000 \\
\hline
\end{tabular}

Link function : Logit.

\section{Table 15: Conscientiousness Goodness-Of-Fit table}

The next table in the results is the Goodness-of-Fit table. This table contains Pearson's chi-square statistic for the model as well as another chi-square statistic based on deviance. These statistics are intended to test whether the observed data is consistent with the fitted model. We start from the null hypothesis that the fit is good. If we do not 
reject this hypothesis (if $p$-value is large), then we conclude that the data and the model predictions are similar and that we have a good model. Conversely, if we reject the assumption of a good fit (if $p<.05$ ), then the model does not fit the data well. The results for our analysis suggest the model does fit very well $p=.615(p>.05)$.

\section{Pseudo R-Square table:}

In linear regression, R2 (the coefficient of determination) summarizes the proportion of variance in the outcome that can be accounted for by explanatory variables, with larger R2 values indicating that more of the variation in the outcome can be explained, up to a maximum of 1 . For ordinal regression models, it is not possible to compute the same R2 statistic as for linear regression, so three approximations are computed instead.

\begin{tabular}{l} 
Pseudo R-Square \\
\begin{tabular}{|l|r|}
\hline Cox and Snell &, 217 \\
Nagelkerke &, 228 \\
McFadden &, 079 \\
\hline
\end{tabular} \\
\hline
\end{tabular}

\section{Table 16: Conscientiousness Pseudo R-Square table}

Here, the pseudo R2 values (e.g. Nagelkerke $=22.8 \%$ ) indicate that conscientiousness explains a relatively large proportion of the variation in students' achievement. The high R2 indicates that a model containing only conscientiousness is likely to be a strong predictor of the outcome for any particular individual student. This affirms that there is a statistically significant and relatively large difference between the average exam grades achieved by highly conscientious students and those of other students who are less conscientious.

\section{Parameter Estimates table:}

The Parameter estimates table describes specifically the relationship between our explanatory variables (IV) and the outcome (DV). 
Parameter Estimates

\begin{tabular}{|c|c|c|c|c|c|c|c|c|}
\hline & \multirow[b]{2}{*}{ Estimate } & \multirow[b]{2}{*}{ Std. Error } & \multirow[b]{2}{*}{ Wald } & \multirow[b]{2}{*}{ df } & \multirow[b]{2}{*}{ Sig. } & \multicolumn{2}{|c|}{$95 \%$ Confidence Interval } \\
\hline & & & & & & & $\begin{array}{l}\text { Lower } \\
\text { Bound }\end{array}$ & $\begin{array}{l}\text { Upper } \\
\text { Bound }\end{array}$ \\
\hline \multirow[t]{4}{*}{ Threshold } & {$[$ Grades $=0$ ] } & 2,234 & ,990 & 5,096 & 1 &, 024 & ,294 & 4,174 \\
\hline & {$[$ Grades $=1]$} & 2,920 & ,999 & 8,549 & 1 &, 003 & ,963 & 4,878 \\
\hline & {$[$ Grades $=2]$} & 3,988 & 1,018 & 15,355 & 1 &, 000 & 1,993 & 5,983 \\
\hline & {$[$ Grades $=3]$} & 5,631 & 1,052 & 28,638 & 1 &, 000 & 3,569 & 7,694 \\
\hline \multirow[t]{9}{*}{ Location } & Q4 &,- 145 &, 185 & ,614 & 1 & ,433 &,- 509 & ,218 \\
\hline & Q9 &,- 231 &, 142 & 2,663 & 1 &, 103 &,- 509 &, 046 \\
\hline & Q15 & 819 & ,202 & 16,395 & 1 &, 000 & ,422 & 1,215 \\
\hline & Q19 & 119 & , 183 & ,421 & 1 &, 516 &,- 240 & 477 \\
\hline & Q23 & 143 &, 135 & 1,124 & 1 & 289 &,- 121 & ,408 \\
\hline & Q25 &,- 035 & ,171 & ,042 & 1 & 837 &,- 371 & 301 \\
\hline & Q27 &,- 359 &, 132 & 7,428 & 1 &, 006 &,- 617 &,- 101 \\
\hline & Q29 &,- 149 & , 163 & ,844 & 1 & ,358 &,- 468 & 169 \\
\hline & Q35 & ,702 & ,218 & 10,333 & 1 & ,001 & ,274 & 1,130 \\
\hline
\end{tabular}

Link function : Logit.

Table 17: Conscientiousness Parameter Estimates table

In the Parameter Estimates table, we see the coefficients, their standard errors, the Wald test and associated p-values (Sig.). The 95\% confidence interval of the coefficients. Items Q15, Q27, and Q35 are statistically significant $(p<.001$ for Q15, $p<.01$ for Q27, and $p<.01$ forQ35), so we would say that for a one unit increase in Q15 (i.e., going from 0 to 1), we expect a 0.82 increase in the ordered log odds of being in a higher grade level given that all of the other variables in the model are held constant. For Q35, we would say that for a one unit increase in Q35, we would expect a 0.7 increase in the $\log$ odds of being in a higher level of exam grades, given that all of the other variables in the model are held constant. This affirms conscientiousness as a positive and significant predictor of the level of academic achievement in the sample. Therefore, $\mathrm{H} 0$ is rejected and we accept $\mathrm{H} 1$, which concludes that conscientiousness is a positive and 
significant predictor of exam grades. The results of the conscientiousness regression test have affirmed the results of the correlation test of conscientiousness and grades which has asserted a positive and significant correlation between conscientiousness scores and grades ( $\mathrm{p}<.001$ for $\mathrm{Q} 15, \mathrm{p}<.05$ for $\mathrm{Q} 25$, and $\mathrm{p}<.001$ for $\mathrm{Q} 35$ ). Based on the results of the correlation and regression tests, we can conclude that conscientiousness factor can be considered as a positive and significant predictor of academic high achievement (high grades) in our sample.

\subsubsection{Extraversion/grades regression analysis}

As a second significant factor has shown to be correlated with exam grades in the sample, Extraversion factor will be tested in the present regression test to examine the validity of this factor in predicting the exam grades by estimating the contribution of this factor in predicting exam grades in the sample. The following hypotheses to be tested are:

- H1 (Research hypothesis): extraversion is a significant negative predictor for exam grades.

- H0 (Null hypothesis): there is no relationship between extraversion and exam grades.

The detailed results of extraversion/ exam grades regression test are as following;

\section{Model fitting information table}

Model Fitting Information

\begin{tabular}{|l|r|r|r|r|}
\hline Model & \multicolumn{1}{|c|}{$\begin{array}{c}-2 \text { Log } \\
\text { Likelihood }\end{array}$} & Chi-Square & df & \multicolumn{1}{c|}{ Sig. } \\
\hline Intercept Only & 588,768 & & & \\
Final & 558,555 & 30,213 & 10 &, 001 \\
\hline
\end{tabular}

Link function : Logit.

Table 18: Extraversion Model Fitting Information table

By comparing the model without any explanatory variables (the baseline or 'Intercept Only' model) against the model with all the explanatory variables (the 'Final' model ) 
we determine whether the model improves our ability to predict the outcome (whether it has significantly improved the fit to the data). The statistically significant chisquare statistic $(p<.05)$ indicates that the final model gives a significant improvement over the baseline intercept-only model. This tells us that the model gives better predictions than if we just guessed, based on the marginal probabilities for the outcome categories, which means that the model does fit well to the data.

\section{Goodness of fit table}

\section{Goodness-of-Fit}

\begin{tabular}{|l|r|r|r|}
\hline & Chi-Square & \multicolumn{1}{c|}{ df } & \multicolumn{1}{c|}{ Sig. } \\
\hline Pearson & 740,061 & 738 &, 472 \\
Deviance & 558,555 & 738 & 1,000 \\
\hline
\end{tabular}

Link function : Logit.

Table 19: Extraversion Goodness-of-Fit

The Goodness-of-fit table table contains Pearson's chi-square statistic for the model as well as another chi-square statistic based on the deviance. These statistics are intended to test whether the observed data are consistent with the fitted model. Null hypothesis is that the fit is good; if we do not reject this hypothesis (if the p value is large), then we conclude that the data and the model predictions are similar and that we have a good model. Likewise, if we reject the assumption of a good fit (if $p<.05$ ), then the model does not fit the data well. The results for our analysis suggest that the model does fit the data very well $p=.472(p>.05)$.

\section{Pseudo R-Square table}

Pseudo R-Square

\begin{tabular}{|r|r|}
\hline Cox and Snell &, 148 \\
Nagelkerke &, 155 \\
McFadden &, 051 \\
\hline
\end{tabular}

Link function: Logit.

Table 20: Extraversion Pseudo R-Square 
In the pseudo R-square table, the pseudo R2 values (e.g. Nagelkerke $=15.5 \%)$ indicate that extraversion explains a relatively large proportion of the variation between students' achievement. The high R2 indicates that a model containing only conscientiousness is likely to be a strong predictor of the outcome for any particular individual student. This affirms the fact that there is a statistically significant and relatively large difference between the average grade level achieved by highly extraverted students and the other students who are less extraverted.

\section{Parameter estimates table}

Parameter Estimates

\begin{tabular}{|c|c|c|c|c|c|c|c|c|}
\hline & & \multirow[b]{2}{*}{ Estimate } & \multirow[b]{2}{*}{ Std. Error } & \multirow[b]{2}{*}{ Wald } & \multirow[b]{2}{*}{ df } & \multirow[b]{2}{*}{ Sig. } & \multicolumn{2}{|c|}{ 95\% Confidence Interval } \\
\hline & & & & & & & Lower Bound & Upper Bound \\
\hline Threshold & {$[$ Grades $=0]$} & $-5,167$ & 1,445 & 12,792 & 1 &, 000 & $-7,998$ & $-2,335$ \\
\hline & {$[$ Grades $=1]$} & $-4,493$ & 1,434 & 9,821 & 1 & ,002 & $-7,304$ & $-1,683$ \\
\hline & [Grades $=2$ ] & $-3,537$ & 1,420 & 6,204 & 1 & ,013 & $-6,319$ &,- 754 \\
\hline & {$[$ Grades $=3$ ] } & $-2,044$ & 1,410 & 2,101 & 1 & , 147 & $-4,808$ & ,720 \\
\hline Location & Q2 & 344 & , 142 & 5,898 & 1 &, 015 & ,066 & ,621 \\
\hline & Q7 &,- 369 &, 179 & 4,265 & 1 & ,039 &,- 719 &,- 019 \\
\hline & Q12 & ,038 & , 162 & ,055 & 1 & ,815 &,- 280 &, 355 \\
\hline & Q14 &,- 589 & , 178 & 10,936 & 1 & ,001 &,- 939 &,- 240 \\
\hline & Q16 &,- 134 & , 156 & ,736 & 1 & 391 &,- 439 & , 172 \\
\hline & Q20 &,- 371 & , 189 & 3,843 & 1 & ,050 &,- 742 & $-5,286 \mathrm{E}-5$ \\
\hline & Q26 & ,313 & , 161 & 3,788 & 1 &, 052 &,- 002 & ,627 \\
\hline & Q28 &,- 001 & , 140 &, 000 & 1 & 993 &,- 276 & 274 \\
\hline & Q30 &,- 148 & , 148 & ,995 & 1 & 319 &,- 438 & 143 \\
\hline & Q33 &,- 281 & |171 & 2,717 & 1 & ,099 &,- 616 & ,053 \\
\hline
\end{tabular}

Table 21: Extraversion Parameter Estimates table 
In the Parameter Estimates table, the significance values of the coefficients between extraversion items and exam grades (p-value) indicate that Q7 and Q14 are statically significant ( $\mathrm{p}<.05$ " $\mathrm{p}=.039$ for $\mathrm{Q} 7$, and $\mathrm{p}=.001$ for Q14") as well as Q20 is marginally significant $(p=.05)$. We would say that for a one unit increase in Q7 (i.e., going from 0 to 1 ), we would expect a 0.37 decrease in the ordered log odds towards a lower level of exam grades. For Q14, we would say that for a one unit increase, we would expect a 0.59 decrease in the log odds towards a lower level of exam grades. Similarly the other marginally significant question of extraversion Q20, we can say that for a one unit increase in Q20, we would expect a 0.37 decrease in the log odds of being toward a lower level of grades. These findings show the negative and significant relationship between extraversion and grades which assert extraversion as a significant negative predictor for academic achievement level in the sample. Therefore, $\mathrm{H} 0$ has to be rejected and we accept $\mathrm{H} 1$ which shows extraversion to be a negative and significant predictor of grades.

The results of the extraversion regression test have confirmed the results of the correlation test of extraversion to grades which has asserted a negative and significant correlation between extraversion scores and grades $(p<.05$ for Q7, $p<.01$ for $\mathrm{Q} 14$, and $p<.05$ for $\mathrm{Q} 16) . \mathrm{H} 3$ has been confirmed by the regression and correlation analysis. In conclusion, the results of our regression and correlation analysis have confirmed $\mathrm{H} 1$, $\mathrm{H} 3$, and disconfirmed (rejected) H2. 


\section{Chapter Five}

\section{Discussion and Conclusion}

\subsection{Discussion}

In investigating the ability of the most important factors of FFM, (conscientiousness, emotional stability and extraversion) to predict academic performance, the first finding of this study was that conscientiousness has appeared as expected to be the factor the most constantly positively and significantly correlated with the academic performance in both of the two academic courses. The results of our correlation test have shown positive significant correlations between conscientiousness and grades in both of academic courses, especially at Q15, Q25, and Q35 ( $r=.389, p<.001$ for Q15, $r=.171$, $p<.05$ for Q25, and $r=.309, p<.000$ for Q35).

The positive significant correlations between these questions and high grades can be interpreted by the characteristics or subfacets of conscientiousness that is the focus of these questions. For example; Q15 (I am demanding in my work) has aimed to evaluate dutifulness and punctuality, Q25 (I do chores as soon as possible) and Q35 (I am always prepared) aimed to evaluate the subfacets of organization and orderliness. These are the subfacets of conscientiousness which are most influential on academic performance; they directly affect academic performance and are the most related to it. These characteristics are vital supportive features for academic success and high achievement, and high scoring in these subfacets leads necessarily to higher academic performance. The benefits of being conscientious are clear. A person who is more conscientious and plans his/her work and practices self-discipline will be more likely to succeed. Conscientious people are focused, aware of the work that needs to get done, and do it in 
a timely and efficient manner. Thus it was normal that these subfacets were the most positively correlated with academic performance and success. As well, the regression test affirmed conscientiousness as a positive significant predictor of exam grades $(\mathrm{p}<$ .000 for $\mathrm{Q} 15$ and $\mathrm{p}<.01$ for Q35). The results of our study are consistently similar to the results of numerous empirical studies which have identified positive relations between this factor and diverse indicators of academic performance. For example, at the broadest level, conscientiousness has been found to be positively associated with GPA, indicating that conscientious students tend to perform better academically than do less conscientiousness ones (Bauer and Liang, 2003; Chamorro-Premuzic and Furnham, 2003a; Conard, 2006; De Fruyt and Mervielde, 1996; Furnham et al., 2003; Goff and Ackerman, 1992; Gray and Watson, 2002; Lievens, Coetsier, De Fruyt and De Maeseneer, 2002; Phillips, Abraham and Bond, 2003; Wolfe and Johnson, 1995).

The Big Five conscientiousness factor has been found to predict more narrow indicators of academic performance such as final grades in an undergraduate course (Conard, 2006; Dollinger and Orf, 1991; Lounsbury, Sundstrom, Loveland and Gibson, 2003; Paunonen and Ashton, 2001a), mid-term exam grades in introductory psychology (Busato et al., 2000; Hair and Hampson, 2006) and in undergraduate statistics classes (Furnham and Chamorro-Premuzic, 2004), written essay grades (Hair and Hampson, 2006) and thesis research grades (Chamorro-Premuzic and Furnham, 2003b). A feasible explanation for these positive and significant relationships is that conscientiousness includes characteristics and subfacets such as dutifulness, order, self-discipline, and thoughtfulness which are essential qualities for high academic achievement. It is often assumed that there is a logical relation between behaviours underlying conscientiousness and academic performance. For example; it seems likely that students who are well-organized, hard-working, and achievement-oriented will perform better than others at typical academic tasks (O'Conner and Paunonen, 2007). Also, teachers generally describe conscientious students as the responsible students. therefore, conscientiousness should be connected to learning and should even be an essential learning resource (De Raad and Schouenbourg, 1996b). Other possible explanation is that the relation between conscientiousness and academic performance has often been 
interpreted in terms of motivation; conscientiousness students are thought to be more motivated to perform well academically than are less conscientiousness students (Chamorro-Premuzic and Furnham, 2005).

The second factor that appeared to be significantly correlated with academic performance in our sample was extraversion. The regression and correlation results have shown a negative and significant relationship between extraversion and academic performance in both of courses of our sample. The negative correlations between this factor and exam grades ranged from $r=-.2, P<.01$ (Q14) to $r=-.175, p<.05$ (Q16) and the regression analysis affirmed this factor as a significant negative predictor of exam grades $(p=.039$ for $\mathrm{Q} 7, p=.001$ for $\mathrm{Q} 14, p=.05$ for $\mathrm{Q} 20)$. This negative relationship between extraversion and exams has been stated in several previous studies investigating the relationship between Big Five factors and academic performance in different education levels. One of these, a study of 247 undergraduate students undertaken by Chamorro-Premuzic and Furnham (2003) investigated the correlation between overall exams marks and the Big Five personality traits throughout a three-year degree program. They found that personality super-traits (especially conscientiousness positively, and extraversion and neuroticism negatively) were significantly correlated with examination grades and were found to account for about $15 \%$ of the variance. Earlier studies (Entwistle, N. and Entwistle, 1970) attributed the relationship between extraversion and academic performance to introverts' greater ability to consolidate learning, lower distractibility, and better study habits. Recent studies (Sanchez-Marin, Rejano-Infante and Rodriguez-Troyano, 2001) suggest that extraverts under-perform in academic settings because of their distractibility, sociability, and impulsiveness.

Moreover, extraversion has been negatively correlated with GPA (Bauer and Liang, 2003; Furnham et al., 2003; Goff and Ackerman, 1992), grades on introductory psychology exams (Busato et al., 2000; Hair and Hampson, 2006) and statistics exams (Furnham and Chamorro-Premuzic, 2004). This negative association has been interpreted as suggesting that introverts spend more time studying, whereas extraverts spend more time socializing (Chamorro-Premuzic \& Furnham, 2005) and that the more 
active social life of extraverts is counter-productive to their study habits (Entwistle \& Entwistle, 1970; Sanchez-Marin et al., 2001).

Despite the numerous studies that have asserted negative correlations between extraversion and academic performance, but the validity of this negative relation has yet to be firmly established, as numerous other studies failed to find any such association. Some research has even identified a positive association between extraversion and some forms academic performance. For example, Rothstein et al. (1994) reported that extraversion was positively associated with classroom participation grades in an MBA program.

Therefore, extraversion can be negatively or positively associated with academic performance depending on other factors such as the academic branch or specialization, or the academic criteria. For example, extraverted students score higher on academic performance criteria when it entails social interaction, teamwork and speaking, such as in presentations and classroom participation. As well as they likely perform better in academic fields which require and show up extraversion qualities like sales, education, and tourism and hotels.

For many reasons the third factor of FFM, emotional stability, was expected to be positively and significantly correlated with academic performance. Highly emotionally stable students tend to perform better under the stress of studying than those with low emotional stability (neurotic) who tend to perform less well under learning loads and stress. This is especially true with respect to exams because they worry beforehand, feel pressured during the exam and dislike being observed, which affects negatively their performance and achievement (Rutger Kappe, 2011). However, in our sample, this factor appeared unexpectedly to be not significantly correlated with exam achievement levels. Despite the small negative correlations observed between emotional stability questions and grades ( $r=-.054, p=.46$ for Q11 and $r=-.141, p=.054$ for Q22), they not significant $p>.05$ for both questions) we can't relay on these correlations to affirm whether there was positive or negative correlations. 
There are three possible explanations for this insignificant correlation. Firstly, our small sample size can affect the significance of the results because in small samples, moderate correlations may misleadingly not reach significance. Conversely, in large samples, small correlations may misleadingly turn out to be significant. Because of this, some researchers think that significance should be reported but should receive less focus.

The second explanation is the fact that there are only two questions concerning emotional stability in the questionnaire (Q11 and Q22), and this may not be sufficient either to evaluate the factor or to associate it reliably with academic performance. If there were more questions concerning emotional stability in the questionnaire, it could be possible that more significant and more expressive correlations between emotional stability and the exam grades would appear.

The third and most likely explanation is that however neuroticism (low emotional stability) has been shown in previous studies to be negatively and significantly correlated with academic performance. For example, neuroticism has been negatively correlated with GPA (Chamorro-Premuzic and Furnham, 2003a; Chamorro-Premuzic and Furnham, 2003b; De Fruyt and Mervielde, 1996) and performance on thesis research (Chamorro-Premuzic and Furnham, 2003b), suggesting that emotionally stable students perform better academically than do more neurotic students. This relation has been interpreted in terms of the debilitating effects of anxiety; under academic evaluation conditions, neurotic individuals are thought to experience anxiety and stress, impairing their performance (Chamorro-Premuzic and Furnham, 2005). However, other studies (O'Conner \& Paunonen, 2006), failed to find a significant relation between neuroticism and academic performance. They found that neuroticism is mostly unassociated with postsecondary academic performance in the empirical literature overall. The mean population correlation between neuroticism and academic performance, estimated by the meta-analysis was $r=-.03$. The $90 \%$ confidence interval for this value was found to range from $r=-.10$ to $r=.04$. This small mean correlation and narrow confidence interval suggest that neuroticism may not be a strong determinant of individual differences in scholastic achievement in general. 
Based on our results and those of previous studies, we can conclude that emotional stability can predict academic performance in only some cases, depending on study conditions and academic assessment criteria. For example, it can be positively associated with academic performance when less stressful studying conditions and criterions, but in general, this factor can provide just a small contribution toward predicting academic performance and it should be considered as less reliable predictor than conscientiousness or extraversion. Since academic performance is a part of and an example of an individual's global performance, these two powerful factors of personality (conscientiousness positively and extraversion negatively) can make a considerable contribution towards predicting overall performance. It can be used as possible practical predictor or indicator of job performance because job performance is also a type of individual performance. Other factors must be considered when employing these dimensions of personality to predict global individual academic or job performance, in order to optimize their usefulness. Some important things to consider include job or academic speciality, academic or job requirements, job or studying conditions, criteria of evaluation, and the nature of the job or the academic specialization. This is because these factors of personality can't be absolute predictors of individual performance in all cases and conditions without restrictions or exceptions because the performance of an individual can vary according to job or academic requirements, loads, circumstances, conditions and performance evaluation criteria.

\subsection{Conclusion}

Personality is the total sum of ways in which an individual feels, thinks, realizes facts, responds in different situations and interacts with others. It affects his/her way of thinking and realizing and it shapes his/her behaviour and actions. An individual's personality consists of a set of broad characteristics and their subfacets such as shyness, aggressiveness, submissiveness, modesty, sociability, nervousness, etc. These characteristics fall into broad groups called personality dimensions or traits, which remain stable throughout most of an individual's life. 
Research has demonstrated that these characteristics tend to occur together in many people. For example, individuals who are sociable tend to be talkative. However, these traits do not always occur together. Personality is complex and varied and each person may display behaviours in several of these dimensions. Much attention has been paid recently to personality traits because it has been shown that they could help in employee selection, matching people to jobs, and in making career development decisions. If certain personality types perform better on specific jobs, then management could use personality tests to screen job candidates in order to hire the most suitable person, to put each employee in the right occupation and to improve job performance.

Over the past century, long efforts to identify the broad traits that govern behaviour resulted in two important models of personality traits as practical guides to classify personality traits; the Myers-Briggs Type Indicator and the Big Five Model. Over the past twenty years, these two approaches have become the dominant frameworks for identifying and classifying traits. In the present study the focus was on the Big Five Factor Model or FFM which has been developed by Costa and McCrae, 1992. It distinguishes personality into five broad traits or dimensions that describe human personality: conscientiousness, neuroticism, extraversion, openness to experience, and agreeableness. The relationship between these factors of personality and individual performance has been studied in many previous works, some of these which confirmed this correlation and others which failed to find a reliable relation between these factors and individual performance.

Interest in the relation between personality differences and individual performance, the present study aimed to examine the relationship between individual performance, as measured by academic achievement in university, as an example of individual performance by the most significant factors of FFM (conscientiousness, neuroticism, and emotional stability as the lowest aspect of neuroticism) which have been shown to be significant predictors of academic performance in many previous studies. There are three broad justifications for studying this relationship. Firstly, academic performance is considered an important indicator of job performance because it predicts future performance in jobs related to the employee's education. Low academic achievement 
predicts low job performance and high academic achievement predicts high job performance. The second justification is that non-cognitive traits (personal traits) which lead to high academic achievement are also required for success in bureaucratic organizations. The third argument is that a credential required by an employer to hire an employee could be for example, grade point average (GPA), a minimum class rank, training evaluation report, graduation from a college of quality, or combination of these (academic achievement and job performance).

Of the three selected factors of FFM, the results of our studies have shown conscientiousness to be the most constantly correlated positively and significantly with academic performance as represented by exam grades. This finding affirmed the first hypothesis (H1) that high scoring in conscientiousness will predict higher academic performance (higher exam grades). This finding was justified by some reasons such as conscientiousness factor contains characteristics or subfacets such as dutifulness, orderliness, self-discipline, and thoughtfulness which are essential qualities that lead to high academic attainment.

The second factor that was found to be significantly correlated with academic performance in our sample was extraversion. This factor was hypothesized to be negatively and significantly correlated with academic performance (H3) and as expected, high scoring in this factor correlated significantly with lower academic performance. This finding was explained in two ways: firstly, that more extraverted students tend to perform lower academically, especially in exams, because they spend less time and attention studying than they do socializing with friends. The second possible explanation is that highly extraverted students perform better in areas that require sociability and talkativeness, such as sales, hotels and tourism, or education.

The third selected factor, emotional stability, was expected to be positively and significantly correlated with academic performance (H2), but the results didn't show any significant relation between this factor and academic performance. This insignificant correlation can be interpreted by some possible justifications such as; the small size of our sample can affect the significance of the correlations in such a way it 
can reach significant in larger sample. In addition, several other studies failed to find significant relation between emotional stability and academic performance. Therefore, this factor can't be considered a reliable predictor of academic performance like the two other selected factors. On the contrary, conscientiousness and extraversion can be thought of as significant indicators of academic performance (conscientiousness positively and extraversion negatively) and by consequence, they can be employed to predict general performance, especially job performance in most cases. Although these factors can reliably predict individual academic or job performance, we can't generalize them to predict overall performance in all conditions and cases without any exceptions or restrictions. Some factors should be considered when employing these personality traits to predict individual performance, such as the job or the academic speciality, academic or job requirements, job or studying conditions, criteria of evaluation, and the nature of the job or academic specialization.

\subsection{Limitations and recommendations}

The present study has some limitations will be summarized as following;

I. The main limitations of this study concern our data set, which only included personality and academic performance data. In addition, only specific data on personality and academic performance was available. Personality was assessed via the Five Factor Model (FFM), which is one of the most widely used and validated personality scales. However, there are a number of leading researchers in the field who prefer to employ other scales, such as the 16PF or Myers-Briggs Type Indicator. On the other hand, the only measure of academic performance was provided by academic grades, although there are other important methods of assessing academic performance such as class participation, absenteeism and course work which may be differentially related to personality traits. Although examination marks can be an important indicator of academic performance which can be a practical and realistic approach, but the other measures of academic performance should also be considered in academic performance evaluation. We recommend that future studies employ other personality scales such as 
the Myers-Briggs Type Indicator and that they consider other measures of academic performance such as class participation, absenteeism and course work as well as exam marks in evaluating academic performance.

II. The present study did not employ any measure of intelligence or cognitive abilities such as an IQ test (this was entirely due to the archival nature of the data). A century of scientific research has shown that general cognitive ability predicts a broad spectrum of important life outcomes, behaviours, and performance, including academic achievement, health-related behaviours, social outcomes, job performance and creativity (Kuncel, N. R., Hezlett, S. A. and Ones, D. S., 2004). Therefore, cognitive ability has a direct effect on and plays a major role in the general performance of an individual. So we can have more beneficial results if cognitive ability is employed with personality factors in predicting academic or job performance. We recommend that future studies involve cognitive tests as well as non-cognitive variables (personality scales) as individual differences in predicting performance.

III. Other factors which can affect academic performance have to be considered when using personality and cognitive abilities to predict academic performance include study habits, learning styles, motivation and interests.

IV. We have a relatively small size sample. This can affect the significance of the results because in small samples moderate correlations may misleadingly not reach significance, whereas in large samples, small correlations may misleadingly turn out to be significant (www.statistics-help-for-students.com). Therefore, we recommend that future studies use a larger number of participants in order to optimize the significance of the results.

V. There are only two questions regarding emotional stability in our questionnaire, which is not sufficient to reliably evaluate this factor or to define with certainty the correlation between this factor and academic performance. Therefore, we recommend that future studies include sufficient assessment items for each personality factor when creating their personality questionnaires. 
VI. Another limitation of this study is the question of whether personality factors which predict academic performance are valid for predicting work performance as well. Although academic performance is an important indicator of job performance, the learning requirements and conditions differ than those of job. As well, the abilities required for success in the real world differ substantially from what is needed to achieve success in the classroom. For this reason, factors of personality which predict academic performance can't be absolute predictors of work performance.

Finally, it is important to remember that behavior involves interactions between a person's underlying personality and situational variables. The situation that a person finds himself or herself in plays a major role in how the person reacts. Therefore, in most cases, people produce responses that are consistent with the existing situation and it isn't necessarily that they will make the same response in all similar situations as well as the responses of people vary depend on the conditions and the circumstances under which they are. 


\section{References}

\section{Bibliography:}

Ackerman, p.L. \& Haggestad, E.D. (1997). Intelligence, personality, and interests: Evidence for overlapping traits. Psychological Bulletin, 121, 219-245.

Aluja, A., Garcia, O., Rossier, J. \& Garcia, L.F. (2005). Comparison of the NEO-FFI, the NEO-FFI-R and and alternative short version of the NEO-PI-R (NEO-60) in Swiss and Spanish samples. Personality and Individual Differences, 38, 591 604.

Bandura, A. (1994). Self-efficacy. In V. S. Ramachaudran (Ed.), Encyclopedia of human behavior,4. New York: Academic Press, pp. 71-81.

Barrick, M.R. \& Mount, M.K. (1991). The big five personality dimensions and job performance: A meta-analysis. Personnel Psychology, 44, 1-26.

Barrick, M.R. \& Mount, M.K. (1993). Autonomy as a moderator of the relationship between the Big Five personality dimensions and job performance. Journal of Applied Psychology, 78, 111-118.

Barrick, M.R., Stewart, G.L., Neubert, M.J. \& Mount, M.K. (1998). Relating member ability and personality to work-team processes and team effectiveness. Journal of Applied Psychology, 83, 377-391.

Barrick, M.R., Mount, M.K. \& Judge, T.A. (2001). Personality and performance at the beginning of the new millennium: What do we know and where do we go next?. International Journal of Selection and Assessment, 9, 9-30.

Bauer, K.W., \& Liang, Q. (2003). The effect of personality and precollege characteristics on first-year activities and academic performance. Journal of College Student Development, 44, 277-290

Bing, M.N. \& Lounsbury, J.W. (2000). Openness and Job Performance in U.S.-Based Japanese Manufacturing Companies. Journal of Business and Psychology, 14, $515-522$.

Blickle, G. (1996). Personality traits, learning strategies, and performance. European Journal of Personality, 10, 337-352. 
Boshoff, C. \& Arnolds, C. (1995). Some antecedents of employee commitment and their influence on job performance. South African Journal of Business Management, 26 (4), 125-135.

Brand, C.R. \& Egan, V. (1989). The 'Big Five' dimensions of personality? Evidence from ipsative, adjectival selfattributions. Personality and Individual Differences, 10, 1165-1 172.

Busato, V.V., Prins, F.J., Elshout, J.J. \& Hamaker, C. (2000). Intellectual ability, learning style, personality, achievement motivation and academic success of psychology students in higher education. Personality and Individual Differences, 29, 1057-1068.

Cattel, R.B. (1946). The description and measurement of personality. Yonkers, New York: World Book.

Cattell, R.B. \& Kline, P. (1977). The scientific analysis of personality and motivation. New York: Academic Press.

Chamorro-Premuzic, T., \& Furnham, A. (2003a). Personality traits and academic examination performance. European Journal of Personality (2003), 17, 237250.

Chamorro-Premuzic, T., \& Furnham, A. (2003b). Personality predicts academic performance: Evidence from two longitudinal university samples. Journal of Research in Personality (2003), 37, 319-338.

Chamorro-Premuzic, T., \& Furnham, A. (2005). Personality and intellectual competence. Mahwah, NJ: Lawrence Erlbaum Associates.

Conard, M.A. (2006). Aptitude is not enough: How personality and behavior predict academic performance. Journal of Research in Personality, 40, 339-346.

Connolly, J. \& Viswesvaran, C. (2000). The role of affectivity in job satisfaction: a meta-analysis. Personality and Individual Differences, 29, 265-281.

Costa, P.T. \& McCrae, R.R. (1985). The NEO Personality Inventory manual. Odessa, FL: Psychological Assessment Resources.

Costa, P.T. \& McCrae, R.R. (1992). NEO-PI-R Professional Manual. Florida: PAR.

Costa, P.T. \& McCrae, R.R. (2004). A Contemplated Revision of the NEO Five-Fac tor Inventory. Personality and Individual Differences, 36, 587-596. 
Costa, P.T., McCrae, R.R., Martin, T.A., Oryol, V.E., Rukaishnikov, A.A, Senin, I.G., Hrebickova, M. \& Urbanek, T. (2004). Consensual Validation of Personality Traits across Culture. Journal of Research in Personality, 38, 179-201.

Day, David V. and Silverman, Stanley B. (1989), "Personality and Job Performance: Evidence on Incremental Validity" Personnel Psychology, Vol. 42, 26-36, 1989

De Fruyt, F. \& Mervielde, I. (1996). Personality and interests as predictors of streaming and achievement. European Journal of Personality, 10, 405- 425.

De Fruyt, F. \& Mervielde, I. (1999). RIASEC types and Big Five traits as predictors of employment status and nature of employment. Personnel Psychology, 52, 701727.

De Raad, B. \& Schouwenburg, H. C. (1996). Personality in learning and education: A review. European Journal of Personality, 10, 303-336.

Digman, J.M. (1989). Five robust trait dimensions: Development, stability, and utility. Journal of Personality, 57, 195-214.

Dollinger, S.J. \& Orf, L. A. (1991). Personality and performance in "personality": Conscientiousness and openness. Journal of Research in Personality, 25, 276284.

Entwistle, N.J. \& Entwistle, D. (1970). The relationships between personality, study methods, and performance. British Journal of Educational Psychology, 40 (2), 132-143.

Eysenck, H.J. (1963). Uses and Abuses of Psychology. Baltimore: Penguin.

Eysenck, H.J. (1967) Personality patterns in various groups of businessmen. Occupational Psychology 41, 249-250.

Eysenck, H.J. \& Eysenck, M.W. (1985). Personality and individual differences: A natural science approach. New York: Plenum.

Farsides, T. \& Woodfield, R. (2003). Individual differences and undergraduate academic success: The roles of personality, intelligence, and application. Personality and Individual Differences, 34, 1225-1243.

Fiske, D.W. (1949). Consistency of the factorial structures of personality rating from different sources. Journal of Abnormal Social Psychology, 44, 329-344. 
Furnham, A. \& Chamorro-Premuzic, T. (2004). Personality and intelligence as predictors of statistics examination grades. Personality and Individual Differences, 37, 943-955.

Furnham, A., Chamorro-Premuzic, T. \& McDougall, F. (2003). Personality, cognitive ability, and beliefs about intelligence as predictors of academic performance. Learning and Individual Differences, 14, 49-66.

Furnham, A., Forde, L. \& Cotter, T. (1998a). Personality and intelligence. Personality and Individual Differences, 24, 187-192.

Furnham, A., Forde, L. \& Cotter, T. (1998b). Personality scores and test taking style. Personality and Individual Differences, 24, 19-23.

Furnham, A. \& Mitchell, J. (1991). Personality, needs, social skills, and academic achievement: A longitudinal study. Personality and Individual Differences, 12, 1067-1073.

Gerald Matthews, Ian J. Deary \& Martha C. Whiteman .Personality traits, second edition (2003). Cambridge University press (2003).

Goff, M. \& Ackerman, P. (1992). Personality-intelligence relations: assessment of typicalintellectual engagement. Journal of Educational Psychology, 84, 537552.

Goh, D. \& Moore, C. (1978). Personality and academic achievement in three educational levels. Psychological Reports, 43, 71-79.

Goldberg, L.R. (1990). An alternative "description of personality": The big-five factor structure. Journal of Personality and Social Psychology, 59, 1216-1229.

Goldberg, L.R. (1993). The structure of phenotypic personality traits: Authors' reactions to the six comments. American Psychologist, 48,1303-1304.

Gray, E.K. \& Watson, D. (2002). General and specific traits of personality and their relation to sleep and academic performance. Journal of Personality, 70, 177206.

Greenhause, J.H. \& Parasuraman, S. (1993). Job performance attrubutions and career advancement prospects: An examination of gender and race effects. Organizational Behavior and Human Decision Processes, 55(2), 273-297.

Hackman, J. \& Oldham, G. (1980). Work redesign. Reading, MA: Addison-Wesley. 
Hair, P. \& Hampson, S.E. (2006). The role of impulsivity in predicting maladaptive behaviour among female students. Personality and Individual Differences, 40, 943-952.

Hart, P.M. (1999). Predicting employee life satisfaction: a coherent model of personality, work, and nonwork experiences, and domain satisfactions. Journal of Applied Psychology, 84, 564-584.

Hayes, T.L., Roehm, H.A. \& Castellano, J.P. (1994). Personality correlates of success in total quality manufacturing. Journal of Business and Psychology, 8, 397-411.

Hirschberg, N. \& Itkin, S. (1978). Graduate student success in psychology. American Psychologist, 33, 1083-1093.

Hough, L.M., Eaton, N.K., Dunnette, M.D., Kamp, J.D. \& McCloy, R.A. (1990). Criterion-related validities of personality constructs and the effect of response distortion on those validities. Journal of Applied Psychology, 75, 581-595.

House, R.J., Shane, S.A. \& Herold, D.M. (1996). Rumours of the death of dispositional research are vastly exaggerated. Academy of Management Review, 21, 203224.

Howard, P.J. \& Howard, J.M. (2004). The Big Five Quickstart: An Introduction to the Five-Factor Model of Personality. North Carolina: Center for Applied Cognitive Studies.

Jang, K.L., Livesley, W.J. \& Vernon, P.A. (1996). Hereditability of the big five personality dimensions and their facets: A twin study. Journal of Personality, 64, 577-591.

Johnson, J.A. (1997). Seven Social Performance Scales for the California Psychological Inventory. Human Performance, 10, 1-30.

Judge, T.A., Cable, D.M., Boudreau, J.W. \& Bretz, R.D. (1995). An empirical investigation of the predectors of excutive career success. Personal Psychology, 48, 485-519. .

Judge. T.A., Higgins, C.A., Thoresen, C.J. \& Barrick, M.R. (1999). The big five personality traits, general mental ability, and career success across the life span. Personnel Psychology, 52, 621-652. 
Kappe, R. (2011). Determinants of success: a longitudinal study in higher professional education.

Kappe, R. \& Flier, H.V.D. (2010). Using multiple and specific criteria to assess the predictive validity of the Big Five personality factors on academic performance. Journal of Research in Personality, 44 (2010), 142-145.

Krilowicz, T.J. \& Lowery, C.M. (1996). Evaluation of personality measures for the selection of textile employees. Journal of Business and Psychology, 11, 55-61.

Kuncel, Nathan R., Hezlett, Sarah A \& Ones, Deniz S. (2004). Academic Performance, Career Potential, Creativity, and Job Performance: Can One Construct Predict Them All?. Journal of Personality and Social Psychology, 86(1), Jan 2004, 148-161Lathey, J. (1991). Temperament style as a predictor of academic achievement in early adolescence. Journal of Psychological Type, 22, 52-58.

Liebert, R.M. \& Spiegler, M.D. (1994). Personality strategies and issues. California: Brooks/Cole.

Lievens, F., Coetsier, P., De Fruyt, F. \& De Maeseneer, J. (2002). Medical students' personality characteristics and academic performance: A five-factor model perspective. Medical Education, 36, 1050-1056.

Locke, E.A. (1976). The nature and causes of job satisfaction. In M. D. Dumnette (Ed.), Handbook of industrial and organizational psychology, 1297-1349.

London, M. \& Stumpf, S. (1982). Managing careers. Reading, Mass.: Addison Wesley Publishing Co.

Lounsbury, J.W., Sundstrom, E., Loveland, J.M. \& Gibson, L.W. (2003). Intelligence, "Big Five" personality traits, and work drive as predictors of course grade. Personality and Individual Differences, 35, 1231-1239.

Lowery, C.M. \& Krilowicz, T.J. (1994). Relationship between nontask behaviours, rated performance and objective performance measures. Psychological Reports, 74, 571-578.

Matthews, G., Deary, I.J. \& Whiteman, M.C. (2003). Personality traits, (2end edition). Cambridge University Press 2003. 
McCrae, R.R. \& Costa, P.T. (1987). Validation of the five-factor model of personality across instruments and observers. Journal of Personality and Social Psychology, 52, 81-90.

Mischel, W. (1968). Personality and assessment. New York: Wiley.

Mount, M.K., Barrick, M.R. \& Stewart, G.L. (1998). Five-factor model of personality and performance in jobs involving interpersonal interactions. Human Performance, 11, 145-165.

Murray R. Barrik, Michael K. Mount \& Timothy A. Judge (2001). Personality and performance at the beginning of the new Millennim: What do we know and where do we go next?. Personality and performance Vol 9 Number $1 / 2$ (March/June 2001).

Norman, W.T. (1963). Toward an adequate taxonomy of personality attributes: Replicated factor structure in peer nomination personality ratings. Journal of Abnormal and Social Psychology, 66, 574-583.

O'Conner, Melissa C. \& Paunonen, Sampo V. (2007), Big Five predictors of postsecondary academic performance. Personality and Individual Differences 43 (2007) 971-990.

Paunonen, S.V., \& Ashton, M.C. (2001a). Big Five predictors of academic achievement. Journal of Research in Personality, 35, 78-90.

Phillips, P., Abraham, C. \& Bond, R. (2003). Personality, cognition, and university students' examination performance. European Journal of Personality, 17, 435448.

Rolfhus, E. \& Ackerman, P. (1999). Assessing individual differences in knowledge: Knowledge, intelligence, and related traits. Journal of Educational Psychology, 91, 511-526.

Rosse, J.G., Stecher, M.D., Miller, J.L. \& Levin, R.A. (1998). The impact of response distortion on pre-employment personality testing and hiring decisions. Journal of Applied Psychology, 83, 634-644.

Rothmann, S. \& Coetzer, E.P. (2003). The Big Five personality dimensions and job performance. SA Journal of Industrial Psychology, 2003, 29 (1), 68-74 
Rothstein, M.G., Paunonen, S.V., Rush, J.C. \& King, G.A. (1994). Personality and cognitive ability predictors of performance in graduate business school. Journal of Educational Psychology, 86, 516-530.

Roy, F. Baumeister, Jennifer, D. Campbell, Joachim I. Krueger \& Kathleen D. Vohs. Does high Self-esteem cause better performance, interpersonal success, happiness, or healther lifestyle?.

Salgado, J.F. (1997). The five-factor model of personality and job performance in the European Community. Journal of Applied Psychology, 82, 30-43.

Sanchez-Marin, M., Rejano-Infante, E. \& Rodriguez-Troyano, Y. (2001). Personality and academic productivity in the university student. Social Behavior and Personality, 29, 299-305.

Schneider, B. (1987). The people make the place. Personnel Psychology, 40, 437453.Cited by: Day, David V. and Silverman, Stanley B. (1989). Personality and Job Performance: Evidence on Incermental Validity. Personnel Psychology, 42 (1989), 25-36.

Schneider, M.H. (1999). The relationship of personality and job settings to job satisfaction. Dissertation Abstracts International: Section B: Science and Engineering, 59, 6103.

Seibert, S.E., Crant, J.M. \& Kraimer, M.L. (1999). Proactive personality and career success. Journal of applied psychology, 84, 416-427.

Shuerger, J.M. \& Kuma, D.L. (1987). Adolescent personality and school performance: a follow up study. Psychology in the Schools, 24, 281-285.

Sinclair, P. \& Barrow, S. (October, 1992). Identifying personality traits predictive of performance. Occupational Testing - Selection \& Development Review (SDR), 8 (5).

Stewart, G.L. \& Carson, K.P. (1995). Personality dimensions and domains of service performance. A field investigation. Journal of Business and Psychology, 9, 365-378.

Strümpfer, D.J.W., Danana, N., Gouws, J.F. \& Viviers, M.R. (1998). Personality dispositions and job satisfaction. South African Journal of Psychology, 28, 92100. 
Tett, R.P. (1998). Is conscientiousness ALWAYS positively related to job performance? The Industrial-Organizational Psychologist, 36(1).

Tett, R.P., Jackson, D.N. \& Rothstein, M. (1991). Personality measures as predictors of job performance: A meta-analytic review. Personnel Psychology, 44, 703-742.

Thoresen, Carl J., Bradley, Jill C., Bliese, Paul D. \& Thoresen, Joseph D. (2004) The Big Five personality traits and individual job performance growth trajectories in maintenance and transitional job stages. Journal of Applied Psychology (2004), 89(5), 835-853.

Tokar, D.M. \& Subich, L.M. (1997). Relative contributions of congruence and personality dimensions to job satisfaction. Journal of Vocational Behaviour, 50, 482-491.

Tupes, E.C. \& Christal, R.E. (1961). Recurrent Personality Factors Based on Trait Ratings. Lackland Air Fource Base, TX: Aeronauticl Systems Division, Personnel Laboratory.

Vinchur, A.J., Schippmann, J.S., Switzer, F.S. \& Roth, P.L. (1998). A meta-analytic review of predictors of job performance for salespeople. Journal of Applied Psychology, 83, 586-597.

Wolfe, R.N. \& Johnson, S.D. (1995). Personality as a predictor of college performance. Educational and Psychological Measurement, 55, 177-185.

Wright, P.M., Kacmar, K.M., McMahan, G.C. \& Deleeuw, K. (1995). Cognitive ability and job performance. Journal of Management, 21, 1129-1139.

Zeinder, M. (1995). Adaptive coping with test situations: A review of the literature. Educational Psychologist, 30, 123-133.

Zeidner, M. \& Matthews, G. (2000). Intelligence and personality. In R. Sternberg (Ed.), Handbook of intelligence (2nd ed., pp. 581-610). New York: Cambridge University Press. 


\section{$>$ Electronic resources :}

- A study on Self Esteem and its Implications, The UK's expert provider of custom essays.

(www.ukessays.com/essays/psychology/a-study-on-self-esteem-and-itsimplications-psychology-essay.php).

- Emotional intelligence. (http://www.mindtools.com/pages/article/newCDV 59.htm).

- How do I interpret data in SPSS for Pearson's $r$ and scatterplots? (www. statistics-help-for-students.com/How do I interpret data in SPSS for_Pearsons $\mathrm{r}$ and scatterplots.htm\#.UZ5HSFLcyMo).

- Low Self-esteem, Health \& Wellness centre - Personal Counseling, University of Toronto Scarborough. (www.utsc.utoronto.ca/ wellness/counselling_lse.html).

- Using Personality Assessments to Hire Employees. (www.Psychometrics.com/using_personality_assessments.pdf).

- What is Locus of control. (www.wilderdom.com/psychology/loc/LocusOfControlWhatIs.html).

\section{$>$ Figures quoted in the thesis:}

- Figure 1 (Five Factors Model of personality): Cybercomputing: The Brain and Thought processes.

(www.cybercomputing.co.uk/MBTI/Big_Five_Personality.htm).

- Figure 2 (Evolution of the number of papers abstracts that linked personality with job performance): APA PsycNet (American Psychological Association). (www.psycnet.apa.org). 


\section{Appendix I:}

\section{Copy of Original Questionnaire Used in Data Collection in French}

Indiquez à l'aide de l'échelle suivante votre degré d'accord avec chacune des propositions :

1

2

3

4

5

\section{Certainement pas - Probablement - Pas Incertain - Probablement - Certainement}

\begin{tabular}{|l|l|}
\hline 1. J'ai le contrôle sur ce qui m'arrive & \\
\hline 2. Je parle beaucoup & \\
\hline 3. Ma vie est agréable & \\
\hline 4. Je remets les choses à leur place & \\
\hline 5. Je connais mes forces & \\
\hline 6. Je termine ce que je commence & \\
\hline 7. Je me sens bien quand je suis avec un groupe & \\
\hline 8. Je suis satisfait de ma vie & \\
\hline 9. Je suis perfectionniste & \\
\hline 10. Quand je fais des plans, je suis à peu près sûr de les réaliser & \\
\hline 11. Je retombe vite sur mes pieds & \\
\hline 12. Je parle à plusieurs personnes dans les partys & \\
\hline 13. Je m'aime comme je suis & \\
\hline 14. J'initie les conversations & \\
\hline 15. Je suis exigeant dans mon travail & \\
\hline
\end{tabular}




\begin{tabular}{|l|l|}
\hline $\begin{array}{l}\text { 16. J'ai beaucoup d'amis } \\
\text { voulais faire dans ma vie }\end{array}$ & \\
\hline 18. J'aime me sentir responsables de mes décisions & \\
\hline 19. J'aime l'ordre et la régularité & \\
\hline 20. Je mets la bonne humeur autour de moi & \\
\hline 21. Je peux changer plusieurs choses importantes dans ma vie & \\
\hline 22. La plupart du temps, je suis relax & \\
\hline 23. J'ai un horaire établi & \\
\hline 24. Si je pouvais revivre ma vie, je ne changerai presque rien & \\
\hline 25. Je fais des corvées dès que possible & \\
\hline 26. Je suis une personne optimiste & \\
\hline 27. Ma chambre est en ordre & \\
\hline 28. Ca ne me dérange pas d'être le centre d'attention & \\
\hline 29. Je suis ponctuel & \\
\hline 30. Je suis silencieux avec des personnes que je ne connais pas & \\
\hline 31. Je sens que je suis une personne de valeur & \\
\hline 32. Je réussis ce que j'entreprends & \\
\hline 33. Je reste à l'écart & \\
\hline 34. Comme étudiant, je suis satisfait & \\
\hline 35. Je suis toujours préparé & \\
\hline 36. Je sens que je n'ai pas grand-chose dont je peux être fier & \\
\hline 37. Je m'adapte à toutes les situations & \\
\hline
\end{tabular}

Table 22: The original questionnaire in French 